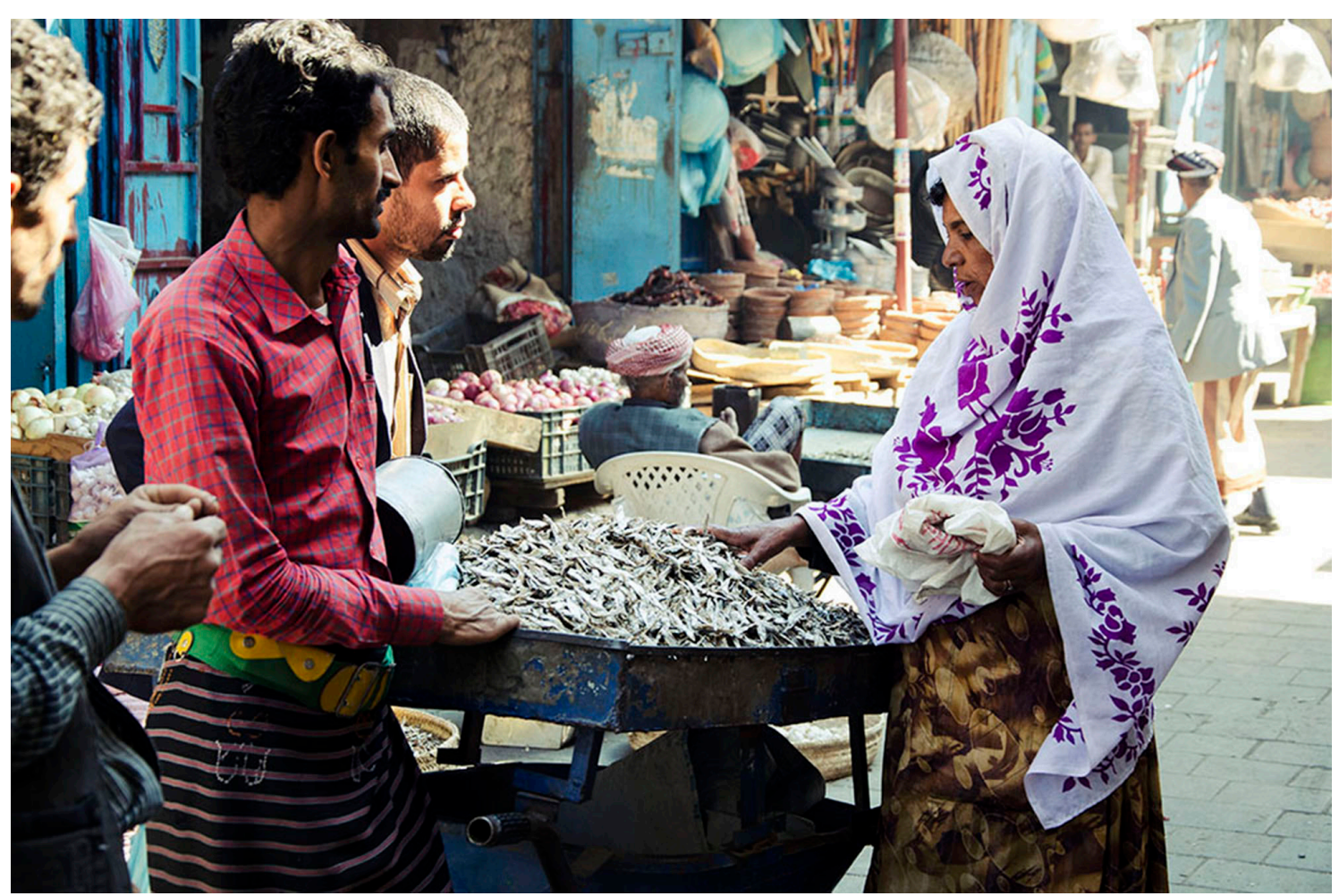

Women buying food at a market in Taiz. @Thana Faroq/Oxfam, 2014

\title{
FROM THE GROUND UP: GENDER AND CONFLICT ANALYSIS IN YEMEN
}

Conflicts and humanitarian crises affect men, women, girls, and boys differently due to their different societal roles and the deep-rooted socio-cultural and economic inequalities which become exacerbated during crises. Men and boys form the vast majority of direct victims of armed conflict and associated impacts like forced recruitment or arbitrary detention. Women bear the burdens of running the households under extreme stress and are often exposed to different forms of gender-based violence. During emergencies, women and girls become more vulnerable as basic services collapse and livelihoods diminish. In order to better understand the impact of armed conflict on men, women, boys, and girls, and the changes that have resulted in gender roles and relationships at household and community levels since the onset of conflict in March 2015, Oxfam, CARE and GenCap in Yemen collaborated to collect and analyse available data to further inform immediate humanitarian response as well as longer-term programming in Yemen.

The assessment covered the governorates of Hajjah, Taiz, Abyan and Aden. The report should be interpreted in conjunction with other assessment reports. The statements in this report do not reflect the position of CARE International, Oxfam Great Britain, or the Gender Standby Capacity Project (GenCap) of the Inter-Agency Standing Committee (IASC). The report only reflects the findings and analysis by the assessment team.

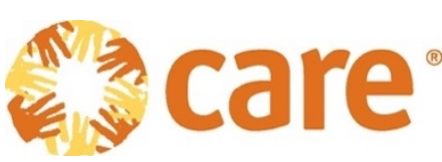




\section{CONTENTS}

Executive summary

1 Introduction 4

2 Context 6

3 Gender roles and relations 13

4 Capacities and vulnerabilities 19

5 Participation in decision making 29

6 Access to services 33

$\begin{array}{ll}\text { Acknowledgements } & 56\end{array}$ 


\section{EXECUTIVE SUMMARY}

Gender relations in Yemen are shaped by diverse religious, cultural, social and political traditions. They are complex, and vary across the north and south of the country, between urban and rural areas, and between different tribes and generations. Historically, women in Yemen have had much less power in society than men. The escalation of the armed conflict in Yemen since March 2015 has created one of the biggest humanitarian crises worldwide. It is likely that the entire population of Yemen will be affected if conflict continues at the current trajectory. In particular, conditions for Yemeni women and girls are deteriorating as the conflict drags on. While the situation in Yemen is rapidly evolving, a general pattern is evident of deteriorating gender relations and the marginalization of women from participation and leadership in decision-making forums.

Due to deep-rooted socio-cultural and economic inequalities at home and in their wider community, conflicts affect men, women, girls, and boys differently. Men and boys make up the vast majority of direct victims of armed conflict, forced recruitment and arbitrary detention, while women and girls - who in normal times bear the burden of running the households and are exposed to different forms of gender-based violence (GBV) - become more vulnerable during emergencies. They are more exposed to malnutrition because they have limited access to resources. They work extra time to increase their income or improve their access to services. Despite these challenges, humanitarian crises can provide opportunities for the promotion of gender equality and transformative gender relationships, because people's life circumstances change along with their gender roles. During the recent conflict, several examples have been documented of women's coping mechanisms, resilience and ability to carve out spaces of agency - hence contradicting the predominant portrayal of Yemeni women as passive victims. Women's increasing roles in distributing community-level humanitarian assistance, hygiene promotion, leading on GBV protection projects and facilitating women's access to services, need to be further nurtured to expand their resilience and peacebuilding potential.

In order to better understand the impact of armed conflict on men, women, boys, and girls, and changes in gender roles and relationships at household and community levels since the onset of conflict in March 2015, Oxfam, CARE and GenCap in Yemen collaborated to collect and analyse available data, with a view to further informing immediate humanitarian response as well as longer-term programming in Yemen. Sound understanding of the differential impact of the conflict on women, men, boys, and girls, helps us adapt our programming to specific life circumstances, capacities and vulnerabilities of men and women, but also to recognize entry points for transformative gender-specific actions that will respond to inequality and injustice in the future.

The assessment built on CARE's and Oxfam's gender assessment tools, and used a combined methodology including a secondary data review, 544 household interviews, 40 focus group discussions, and 32 in-depth interviews with 'key informants' - activists and leaders. The assessment was supplemented by case studies/stories collected from participants and civil society to validate and exemplify the research findings. The geographical scope of the assessment included the areas in Yemen with the most severe needs - Aden, Taiz, Hajjah and Abyan governorates.

The thematic scope of the assessment covered four gender-specific domains, including a) gender roles and relations, b) capacities and vulnerabilities, c) participation in decision making (at community and intra-household levels), and d) access to services and assistance. The report concludes with guidance on how to implement humanitarian response and longer-term programming in a way that better supports women's and men's, boys' and girls' different needs and aspirations, strengthens gender equity and equality, and contributes to the long-term transformation of power imbalances between women and men. 


\section{INTRODUCTION}

Gender inequality and the specific barriers faced by Yemeni women and girls in achieving their full potential have long been recognized as both underlying and direct causes of food insecurity, malnutrition and poverty in Yemen. While the Yemen crisis is evolving rapidly, a general pattern of deteriorating gender relations and the marginalization of women from participation and leadership in decision-making forums appear evident. Advances made in recent years to address gender inequality in Yemen are at risk of being reversed. Such advances include recognition of the importance of including women in peace talks as a driver for peace and security in a country that has long been affected by multi-faceted conflicts. Secondly, there are reports of increasing marginalization of women as well as increasing levels of gender-based violence (GBV), and fears have been expressed that this will serve to further reinforce gender inequality in the long-term reconstruction phase.

\section{BACKGROUND}

A scoping study was conducted by CARE and Inter-Agency Standing Committee (IASC) Gender Capacity Standby Project (GenCap) to review and assess available information on the impact of the conflict on gender roles and relations, and the consequently different needs of women, girls, boys, and men. ${ }^{1}$ It found that while there was good pre-conflict information on gender issues in Yemen, most assessments conducted since March 2015 have been 'gender blind'. The study concluded that further gender and generational analysis is needed to ensure that humanitarian programming in Yemen is aware of and responsive to changes in gender relations, so that it meets the different needs of women, men, boys, and girls.

Humanitarian programmes in all sectors need to work to safeguard the progress on gender equality that was made prior to the emergency, continue advancing that progress, and lay the foundations for sustainable and gender-equitable recovery and reconstruction, and for the participation of women in peace talks and in the protection of their social and economic rights.

\section{METHODOLOGY}

The overall objective of the assessment was to inform immediate humanitarian response and longer-term programming in Yemen, by identifying and documenting changes in gender roles and relationships at household and community levels since March 2015. The project was implemented between 10 February and 9 May 2016. Field data collection was implemented between 28 March and 15 April 2016. The assessment built on CARE's and Oxfam's gender assessment tools, and used a combined methodology including a secondary data review, household interviews, focus group discussions, in-depth interviews with or 'key informants', and case studies/stories. The methodology is innovative in so far as it systematically triangulates these qualitative and quantitative data sets. The full secondary data review report is available in a standalone document.

The geographical scope of the assessment included the areas in Yemen with severe needs governorates of Aden (Dar Saad and Al Boriqah districts), Taiz (Shmayateen and Taziha districts), Hajjah (Abs and Shafar districts) and Abyan (Zonjobar and Khanfer districts). The assessment obtained a sample of 544 household interviews, including 280 female (51\%) and 264 male interviewees (49\%), with an equal number of interviews in urban and rural settings. Urban settings were divided into four geographical quadrants. In each quadrant, the gender- 
mixed field team ( $50 \%$ female) randomly selected and interviewed a predetermined number of households. In the rural settings, a non-probability sampling method was used.

In addition to the household interviews, 40 focus group discussions were conducted, including 16 discussions each with males and females (separate discussions with host communities and internally displaced people), as well as eight discussions with marginalized groups (separate discussions with males and females), and eight discussions with female and male youth representatives (only urban settings). Thirdly, in each of the four governorates, eight in-depth 'key informant' interviews were conducted with activists and local leaders (32 in total). The assessment was supplemented by case studies/stories collected from participants and civil society to validate and exemplify the research findings. Finally, enumerators shared their direct observations during the field work, and feedback was collected from participants and civil society to ensure endorsement and validation of the research findings.

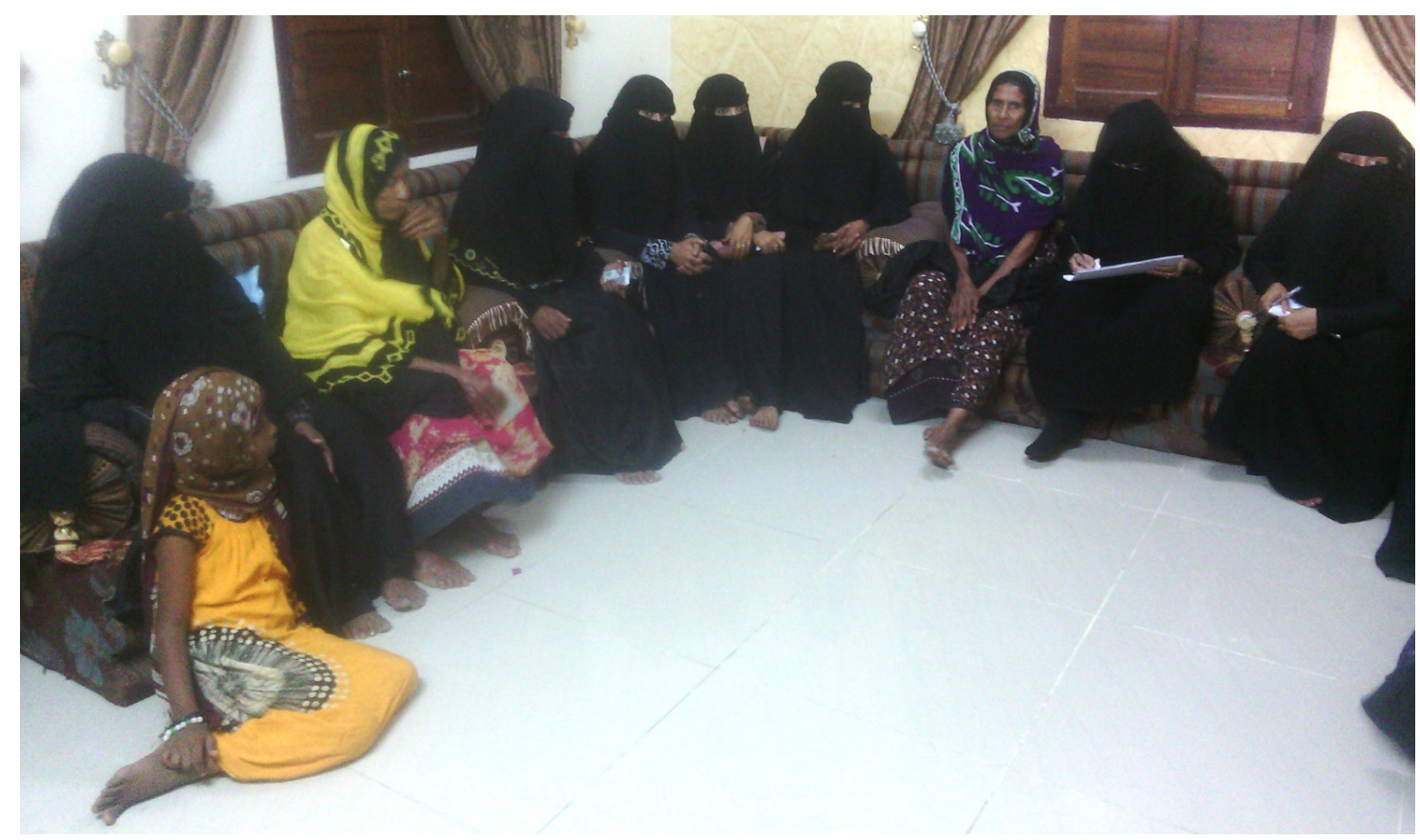

Female focus group discussion in Abyan. @Grassroots Yemen, April 2016

Following completion of the draft analysis, a validation workshop was held in Sana'a, Yemen. The workshop included 36 participants: one representative from each of 10 national NGOs, 15 international NGOs (INGOs), 6 UN agencies and 5 government representatives. The aim of the workshop was to review the initial findings of the analysis, discuss implications for programming and identify areas for further analysis. The reflections and learnings from the workshop are integrated into this report.

\section{LIMITATIONS OF THE ASSESSMENT}

The sample was designed to be representative at the geographical area level. For the urban and rural areas of the four covered governorates, the sample allows for a confidence level of $90 \%$ and a margin of error of plus/minus $10 \%$. The assessment is not representative at town/village level. Furthermore, the assessment does not aim to be representative of findings for more or less conflict-affected areas.

\section{Gender}

Respondents were gender-balanced; $51 \%$ of the household representatives interviewed were females above 18 years of age. Respondents were not limited to 'heads of households'. The 
views expressed by women and men reflected their individual perception of the overall household situation.

\section{Dynamics}

The situation in Yemen is quite dynamic, limiting the timespan validity of the information contained in this assessment. Results should be reinterpreted in the light of future demographic changes relating to displacement.

\section{REPORT STRUCTURE}

After the executive summary and introduction, a context section introduces the background of the research and sets the baseline, pre-March 2015 crisis, including demographics and crisis impact, trends, and main vulnerable groups in Yemen. The key findings and analysis of the report are presented under four gender-specific domains, as follows:

- Gender roles and relations

- Capacities and vulnerabilities

- Participation in decision making (at community and intra-household levels)

- Access to services and assistance (including mobility)

Each section provides pre-crisis context and explores the impact of the crisis at community and household levels. The report concludes with guidance on how to implement humanitarian response in a way that better supports the needs and aspirations of males and females of different ages, strengthens gender equity and equality, and contributes to the long-term transformation of power imbalances between women and men.

\section{CONTEXT}

\section{PRE-CONFLICT DEMOGRAPHIC BASELINE}

In the 20 years after unification, Yemen's population grew by $58 \%$ from 16 million to 25.9 million. ${ }^{2}$ Population growth put pressure on public services and public utilities as well as the labour market. ${ }^{3}$ Youth (people aged $15-29$ ) represent $45 \%$ of the population. ${ }^{4}$ Before 2015 , about $42 \%$ of the population of Yemen lived below the poverty line, two-thirds of Yemeni youth were unemployed, and basic social services were in urgent need of support. ${ }^{5}$

Even before the current crisis, Yemen faced high levels of humanitarian need, with 16 million people (61\% of the population) requiring humanitarian assistance in late 2014 as a result of years of under-development, environmental decline, intermittent conflict and weak rule of law, including widespread violations of human rights. Following the political turmoil that led to the resignation of President Ali Abdullah Saleh in early 2012, an uneven political transition got underway. This process unravelled in late 2014, when Ansar-u-Allah effectively took control of Sana'a and national institutions, following a Houthi military expansion in the north. ${ }^{6}$ From 2012 to 2014 , real GDP per capita (already the lowest in the Arab world) declined from $\$ 590$ to $\$ 500 .^{7}$ 


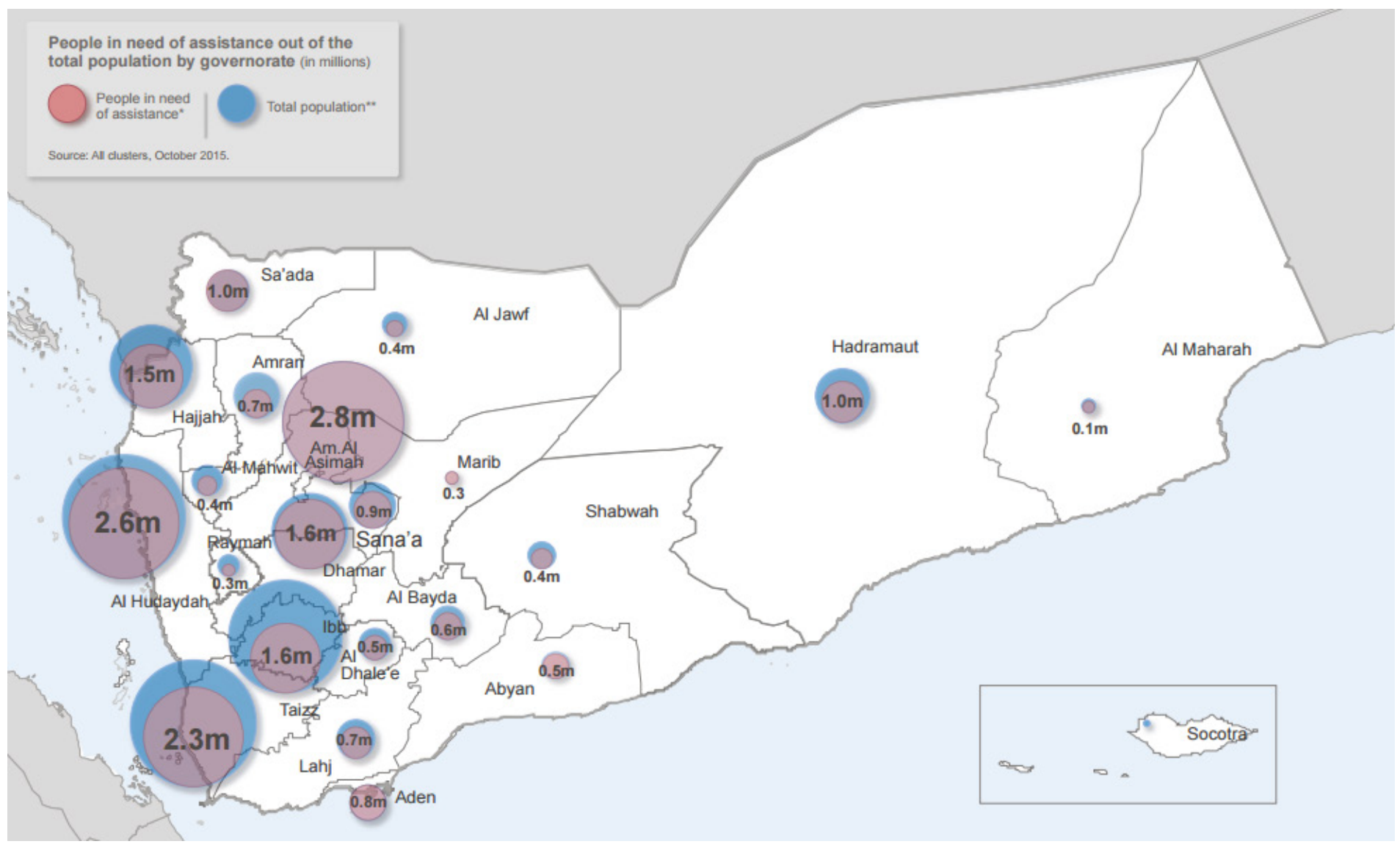

Source: OCHA $2015^{8}$

Throughout this period, 10.5 million people did not have enough to eat. Over 13 million people lacked access to clean water, and 8.5 million lacked access to healthcare. Humanitarian assistance contributed to some improvements during this time, including an estimated $10 \%$ decrease in acute malnutrition rates in 2014 , and the rollout of a durable solutions programme for the long-term displaced. ${ }^{9}$ In 2014 , prior to the current conflict, 80,000 people were displaced due to localized conflicts. An additional 335,000 Yemenis remained in protracted displacement, mainly in the north. ${ }^{10}$

Yemen's population is young. The proportion of people in the interviewed households under the age of 18 is $74 \%$, while the proportion of individuals aged 61 and older is $2 \%$. About $92 \%$ of households in Yemen are headed by men. ${ }^{11}$ Households in Yemen are large, with almost onequarter consisting of 9 or more members. The overall average size of the 544 interviewed households is 6.7, in line with Ministry of Public Health and Population (MoPHP) statistics for 2015 , with an average of 6.6 members in urban areas and 6.7 in rural areas. The household size is the largest in Taiz ( 7.5 members) and lowest in Abyan (5.7 members). In larger households, economic resources are often more limited. Female-headed households are typically poorer than male-headed households. ${ }^{12}$ 
Figure 1: Household composition in urban and rural settings

Rural

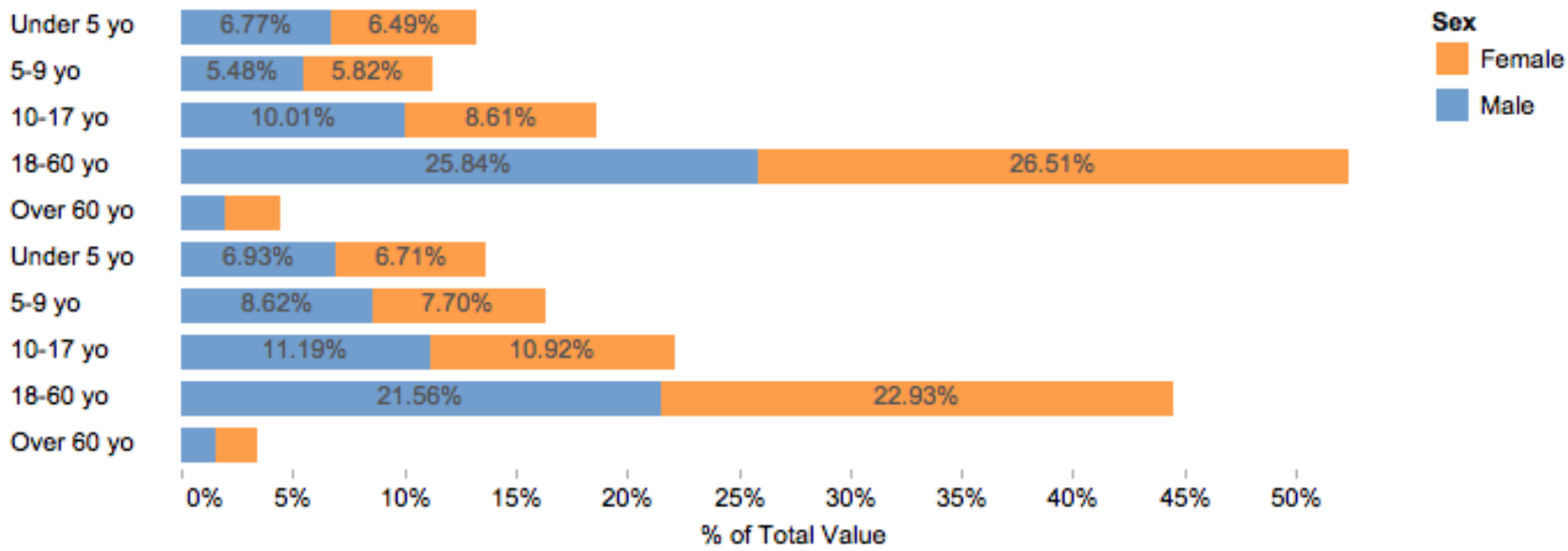

Source: Household interviews

\section{CONFLICT IMPACT BY DEMOGRAPHIC GROUP}

\section{Key figures}

- $80 \%$ of the population, 21.2 million people, are in need of humanitarian assistance, with 14.1 million in need of protection assistance.

- Of the 2.76 million IDPs, about half of are concentrated in Aden, Taiz, Hajjah and Al Al Dhale'e governorates, with additional significant populations in Abyan, Al Bayda, Ibb, Sa'ada and Amran.

- At least 121,000 people, mainly third-country nationals, have fled the country.

- 6,000 people have been killed since the coalition entered the conflict in March 2015, almost half of them civilians.

- Since March 2015, 30 civilians are made casualties of war every day in Yemen.

- IDPs are sheltering in 260 schools, preventing 13,000 children from accessing education.

\section{CONFLICT TRENDS}

Since the end of March 2015, the escalation of the armed conflict in Yemen has created one of the biggest current humanitarian crises worldwide. ${ }^{13}$ The consequences of the conflict for affected populations have been exacerbated by sociopolitical inequalities, gender inequality and discrimination, and civil and economic structures. According to the UN Office for the Coordination of Humanitarian Affairs (OCHA), it is likely that the entire population of Yemen will be affected if conflict continues at the current trajectory.

Coping mechanisms are already stretched to breaking point. Displacement has contributed to rising needs across sectors - particularly shelter and non-food items, for which about 2.8 million IDPs and host community members currently require support. Conflict and import restrictions since mid-March 2015 have accelerated declines in living conditions, and reversed fragile improvements recorded in several sectors in late 2014. 19.3 million people lack access to safe 
water, 14.1 million people lack access to basic healthcare and 1.8 million children lack access to education. ${ }^{14}$

As IDPs move throughout the country in search of safety and shelter, rental prices are rising, creating a further drain on the economic resources of displaced families. Many IDPs are staying with relatives or friends, a situation that places additional stress on already vulnerable households. ${ }^{15}$ In particular, conditions for Yemeni women and girls are deteriorating as the conflict in Yemen drags on. The stress and chaos of the crisis, coupled with entrenched gender inequality, have left women and girls extremely vulnerable to violence, abuse and exploitation. ${ }^{16}$

The surge in conflict in 2015 has taken a severe toll on civilians' lives and basic rights. Between March and October 2015, health facilities have reported more than 32,200 casualties - many of them civilians. In the same period, the Office of the UN High Commissioner for Refugees $(\mathrm{OHCHR})$ has verified 8,875 reports of human rights violations - an average of 43 violations every day.

Verified incidents of child death or injury from March to September 2015 are five times higher than 2014 totals. ${ }^{17}$ According to the UN, over 14 million people require protection assistance in Yemen, including IDPs, refugees, migrants and conflict-affected people. Civilians are facing increased risk of death, injury, displacement and psychological trauma. The current estimate represents a $23 \%$ increase since June 2015 . The following populations are especially vulnerable: people living in poverty, women, children, the elderly, people living with disabilities, people living without protection of their family, minority groups and survivors of human rights violations. $^{18}$

\section{Main vulnerable population groups}

Figure 2: Needs and target requirements

\begin{tabular}{|c|c|c|c|c|c|c|c|c|c|c|c|}
\hline & \multirow{2}{*}{$\begin{array}{l}\text { TOTAL } \\
\text { People in need }\end{array}$} & \multirow[b]{2}{*}{$\begin{array}{l}\text { People } \\
\text { targeted }\end{array}$} & \multicolumn{2}{|c|}{ BY SEX \& AGE } & \multicolumn{4}{|c|}{ BREAKDOWN OF PEOPLE TARGETED } & \multicolumn{2}{|c|}{ TOTAL REQUIREMENTS } & \multirow[b]{2}{*}{$\begin{array}{l}\text { Total } \\
\text { (USS) }\end{array}$} \\
\hline & & & Men & Women & Boys & Girls & $\begin{array}{c}\text { Cluster } \\
\text { Total }\end{array}$ & $\begin{array}{c}\text { Refugees } \\
\& \& \\
\text { Migrants }\end{array}$ & Cluster & $\begin{array}{l}\text { Refugees } \\
\& \\
\text { Migrants }\end{array}$ & \\
\hline $\begin{array}{l}\text { Food Security \& } \\
\text { Agriculture }\end{array}$ & $14.4 \mathrm{M}-0$ & $-8.9 \mathrm{M}$ & $2.1 \mathrm{M}$ & $2.0 \mathrm{M}$ & $2.4 \mathrm{M}$ & $2.3 \mathrm{M}$ & $8.8 \mathrm{M}$ & $0.07 \mathrm{M}$ & $\$ 847.1 \mathrm{M}$ & $\$ 1.4 \mathrm{M}$ & $\$ 848.5 \mathrm{M}$ \\
\hline T. WASH & $19.4 \mathrm{M}$ & $7.4 \mathrm{M}$ & $1.5 \mathrm{M}$ & $1.5 \mathrm{M}$ & $2.2 \mathrm{M}$ & $2.1 \mathrm{M}$ & $7.4 \mathrm{M}$ & $0.07 \mathrm{M}$ & $158.4 \mathrm{M}$ & $1.7 \mathrm{M}$ & $160.1 \mathrm{M}$ \\
\hline Health & $14.1 \mathrm{M} \quad \odot$ & $10.6 \mathrm{M}$ & $2.0 \mathrm{M}$ & $2.3 \mathrm{M}$ & $3.2 \mathrm{M}$ & 3.1M & $10.5 \mathrm{M}$ & $0.09 \mathrm{M}$ & $182.3 \mathrm{M}$ & $6.9 \mathrm{M}$ & $189.2 \mathrm{M}$ \\
\hline Nutrition & $3.0 \mathrm{M}$ & $3.0 \mathrm{M}$ & 0 & $0.43 \mathrm{M}$ & $1.0 \mathrm{M}$ & $0.96 \mathrm{M}$ & $3.0 \mathrm{M}$ & 0 & $178.9 \mathrm{M}$ & 0 & $178.9 \mathrm{M}$ \\
\hline Shelter/NFIs/CCCM & $2.8 \mathrm{M}$ & $2.0 \mathrm{M}$ & $0.52 \mathrm{M}$ & $0.58 \mathrm{M}$ & $0.41 \mathrm{M}$ & $0.43 \mathrm{M}$ & $1.9 \mathrm{M}$ & $0.07 \mathrm{M}$ & $156.2 \mathrm{M}$ & $6.8 \mathrm{M}$ & $163.0 \mathrm{M}$ \\
\hline 19) Protection & $14.1 \mathrm{M}$ & $5.6 \mathrm{M}$ & $1.5 \mathrm{M}$ & $1.6 \mathrm{M}$ & $1.2 \mathrm{M}$ & $1.19 \mathrm{M}$ & $5.4 \mathrm{M}$ & $0.15 \mathrm{M}$ & $52.4 \mathrm{M}$ & $38.4 \mathrm{M}$ & $90.8 \mathrm{M}$ \\
\hline (9) Child Protection & $7.4 \mathrm{M}$ & $2.0 \mathrm{M}$ & $0.10 \mathrm{M}$ & $0.10 \mathrm{M}$ & $0.89 \mathrm{M}$ & $0.89 \mathrm{M}$ & $2.0 \mathrm{M}$ & 0 & $22.6 \mathrm{M}$ & 0 & $22.6 \mathrm{M}$ \\
\hline 아 GBV* & $0.59 \mathrm{M}$ & $0.59 \mathrm{M}$ & $0.08 \mathrm{M}$ & $0.23 \mathrm{M}$ & $0.09 \mathrm{M}$ & $0.19 \mathrm{M}$ & $0.59 \mathrm{M}$ & 0 & $9.1 \mathrm{M}$ & 0 & $9.1 \mathrm{M}$ \\
\hline DI] Educotion & $3.0 \mathrm{M}$ & $1.8 \mathrm{M}$ & $0.01 \mathrm{M}$ & $0.01 \mathrm{M}$ & $0.79 \mathrm{M}$ & $0.96 \mathrm{M}$ & $1.8 \mathrm{M}$ & 0 & $27.5 \mathrm{M}$ & 0 & $27.5 \mathrm{M}$ \\
\hline Derly Recovery & $6.9 \mathrm{M}$ & $3.4 \mathrm{M}$ & $0.93 \mathrm{M}$ & $0.89 \mathrm{M}$ & $0.82 \mathrm{M}$ & $0.79 \mathrm{M}$ & $3.4 \mathrm{M}$ & 0 & $51.1 \mathrm{M}$ & 0 & $51.1 \mathrm{M}$ \\
\hline ดे Logistics & - & - & - & - & - & - & - & - & $39.0 \mathrm{M}$ & - & $39.0 \mathrm{M}$ \\
\hline ETC* & - & - & - & - & - & - & - & - & $1.8 \mathrm{M}$ & - & $1.8 \mathrm{M}$ \\
\hline Coordination \& Safety & - & : & - & - & - & - & - & $\cdot$ & $17.6 \mathrm{M}$ & - & $17.6 \mathrm{M}$ \\
\hline 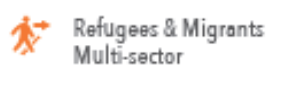 & $0.46 \mathrm{M}$ & $0.46 \mathrm{M}$ & $0.25 \mathrm{M}$ & $0.10 \mathrm{M}$ & $0.07 \mathrm{M}$ & $0.04 \mathrm{M}$ & $0.46 \mathrm{M}$ & $0.46 \mathrm{M}$ & - & & 0 \\
\hline TOTAL & $21.2 \mathrm{M}$ & $13.6 \mathrm{M}$ & $2.8 \mathrm{M}$ & $2.6 \mathrm{M}$ & $4.0 \mathrm{M}$ & $3.8 \mathrm{M}$ & $13.2 \mathrm{M}$ & $0.46 \mathrm{M}$ & $\$ 1,742.9 \mathrm{M}$ & $\$ 55.2 \mathrm{M}$ & $\$ 1799.3 \mathrm{M}$ \\
\hline
\end{tabular}

Source: Humanitarian Response Plan 2016 
Conflict exposes civilians to heightened risks of death, injury, displacement and psychological trauma. An estimated 12.4 million people are living in districts affected by recurrent airstrikes, anti-aircraft fire or armed clashes, including 2.3 million IDPs and 460,000 vulnerable host community residents. ${ }^{19}$ The most heavily conflict-affected districts are concentrated in Taiz, Sa'ada, Hajjah, Marib and Sana'a. The highest reported displacement concentrations are in Aden, Taiz, Al Dhale'e and Hajjah. ${ }^{20}$ In focus group discussions in Abyan, participants reported that large areas of agricultural land are now inaccessible due to landmines.

Displaced women often bear additional burdens including caring for injured household members, dealing with the loss of family breadwinners, and challenges in accessing assistance, especially outside their communities. A UN-held estimate is that as many as $30 \%$ of displaced women may now be heading their families. ${ }^{21}$

Figure 3: Household status and displacement

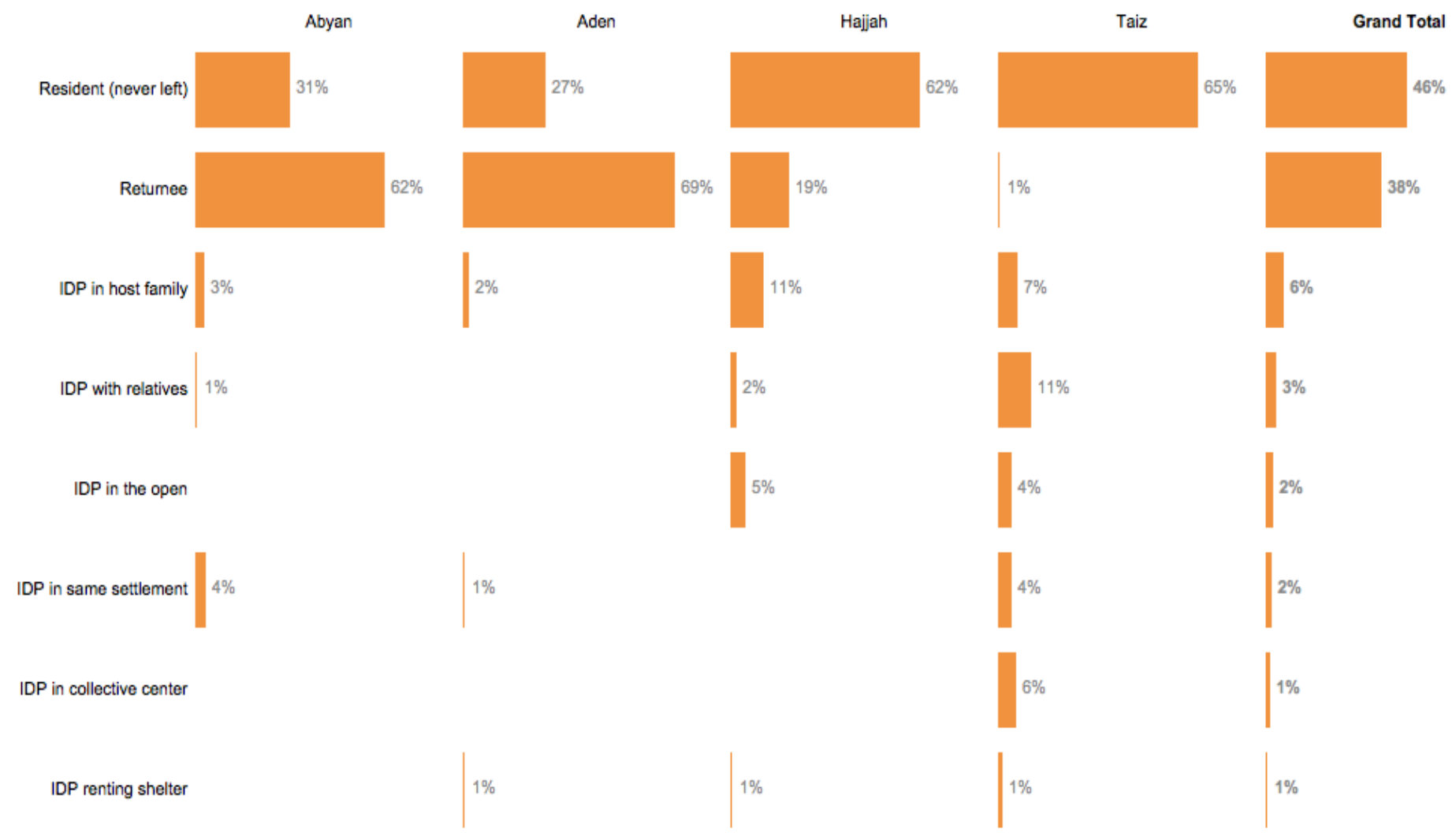

Source: Household interviews

Of the 544 households surveyed, $15 \%$ are currently displaced by conflict, $38 \%$ returned to their homes after displacement, while $46 \%$ currently were resident at their place of origin. Of the interviewed IDPs, $81 \%$ are living with neighbours or relatives, which places additional stress on often already vulnerable families. IDPs living in the open or in unprotected spaces are perhaps the most vulnerable to further harm; in Hajjah, $27 \%$ of the interviewed IDP population are living in the open (13\% in Taiz). These risks include a large threat of GBV. Also of concern are overcrowding and lack of clean water and sanitation services, further exacerbated by the lack of healthcare facilities and food shortages. 260 schools are currently sheltering IDPs, mainly in Taiz and $\mathrm{lbb} .^{22}$

Interviews in Hajjah and Taiz revealed that a substantial proportion of the people displaced by the current conflict are from marginalized groups ('Muhamasheen'), which are considered to be particularly vulnerable, especially in Taiz, where they have reduced access to income and 
education. The exposure to violence and displacement, and further reduced access to resources exacerbate their experience of marginalization and discrimination.

There are also an estimated 460,000 refugees and migrants in Yemen who need humanitarian assistance. Female focus group discussions in Aden confirmed that refugees and migrants often face greater difficulty in accessing services than Yemeni nationals. Those with the most severe needs are mainly located in coastal governorates and major urban centres. Compared to the 2015 Humanitarian Needs Overview, the number of refugees and migrants in need of assistance has fallen by about half due to the suspension of forcible large-scale expulsions of migrants from Saudi Arabia. If expulsions resume, the number of people in need could rise quickly. Despite the surge in conflict, 60,000 new refugees and migrants arrived in Yemen in 2015 (i.e. the same as the pre-conflict level). Vulnerable refugees and migrants need a range of services, including referrals to other services such as GBV counselling and child protection. ${ }^{23}$

The humanitarian situation in Yemen increases the risks to women and girls of violence, harassment and abuse, sexual and labour exploitation, as well as early, child, and forced marriage. It is likely that the current conflict will worsen the level of GBV, increasing the need for adequate protection and support mechanisms. ${ }^{24}$ Recorded GBV incidents show an upward trend since March 2015, with 70\% more incidents reported in September than March 2015. Overall, women are also more acutely affected than men by declines in living conditions and service availability. ${ }^{25}$

According to the focus group discussions, IDP women are most vulnerable, as many have lost their property and access to livelihoods as a result of the conflict. Women are more vulnerable where they are living in makeshift shelters (most common in Taiz and Hajjah), where there is insufficient access to basic services (Abyan and Hajjah) and in areas controlled by Islamist groups (Abyan). Participants in focus groups reported that girls from marginalized groups are especially at risk from violence, frequent harassment by armed groups at checkpoints, and kidnapping.

Survivors of GBV in Yemen often have no access to support services or knowledge of where existing services are. This places survivors at particular risk of fatality or complications from physical injury, HIV contraction, sexually transmitted infections and pregnancy - all of which could be prevented if they were able to access appropriate care. In general, women and girls in Yemen are often denied access to resources, opportunities and services - this is in itself another form of GBV. ${ }^{26}$

An important trend is the increase in the number of pregnant and lactating women: $23.4 \%$ of households reported having pregnant and lactating women in their family before the crisis started in March 2015, compared to $44.3 \%$ today. While this trend is true for all interviewed population groups, it the highest for households that did not leave their place of residence because of the conflict (residents, 15.8\% increase), and lowest for IDP households (5.3\% increase). Focus group discussion participants confirmed these findings, reporting that husbands are spending more time at home due to loss of employment, and that many families do not have access to contraceptives. During the validation of the assessment findings, participants also shared that community leaders are encouraging women to reproduce because the country needs offspring to recover after the war. 


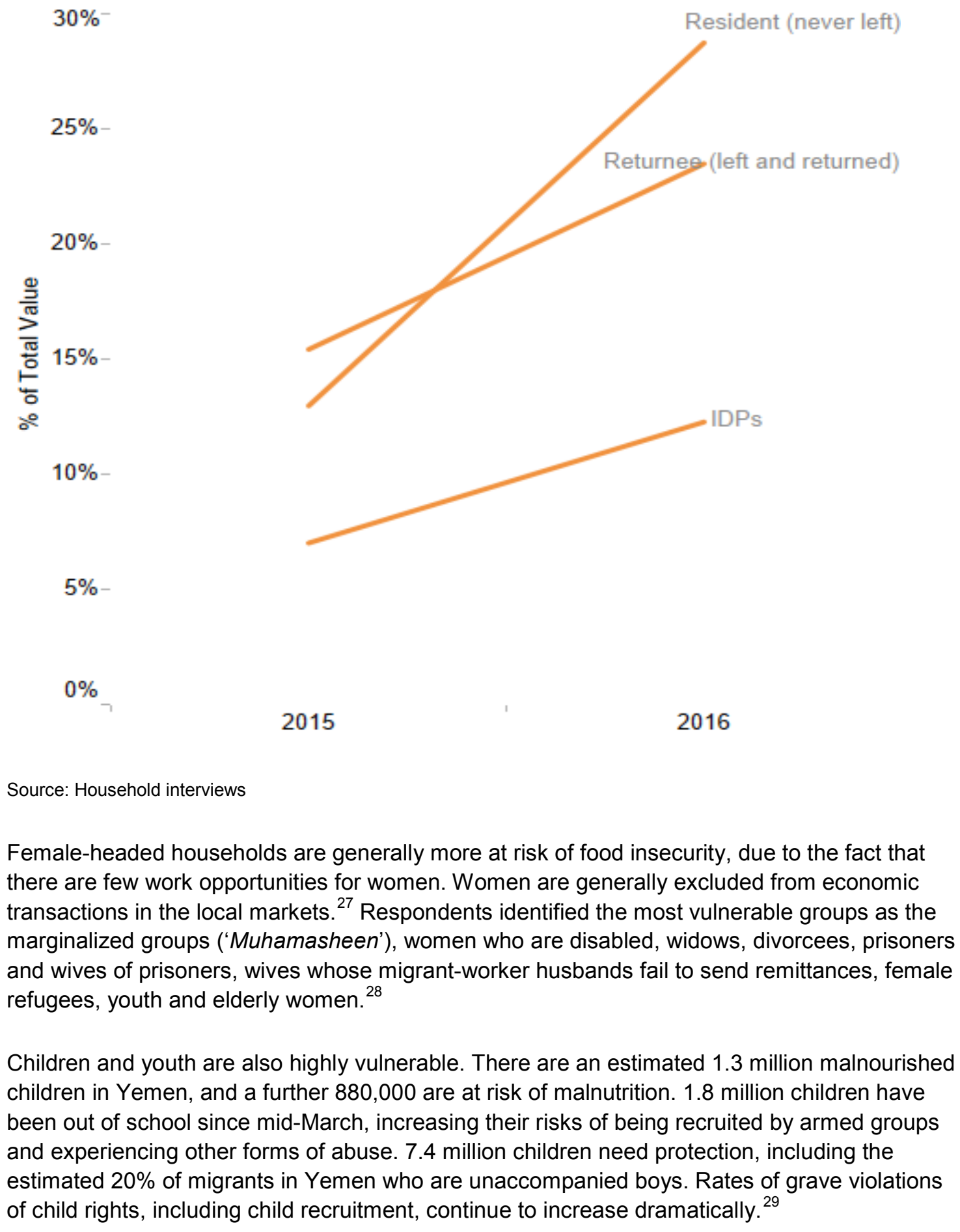

Youth, particularly young men, are not only vulnerable to recruitment by armed groups, they are also increasingly likely to carry weapons. Participants in the focus group discussions cited this as one of the most serious emerging problems. Key informants reported that one of the armed groups used weapons as prizes in their cultural programmes to honour young achievers who are not yet members of their group. And in the absence of employment for young people, joining armed groups in order to have a source of income is becoming more attractive to youth. In one focus group discussion, a girl indicated her readiness to join an armed group as long as it would bring an income for her family.

People with special needs (physical disabilities, mental disorders or chronic illnesses) are the most vulnerable persons among these population groups. Of the 544 interviewed households, 
$6.7 \%$ reported having household members with special needs, with the highest number in Hajjah (7.3\%) and the lowest in Abyan (5.7\%).

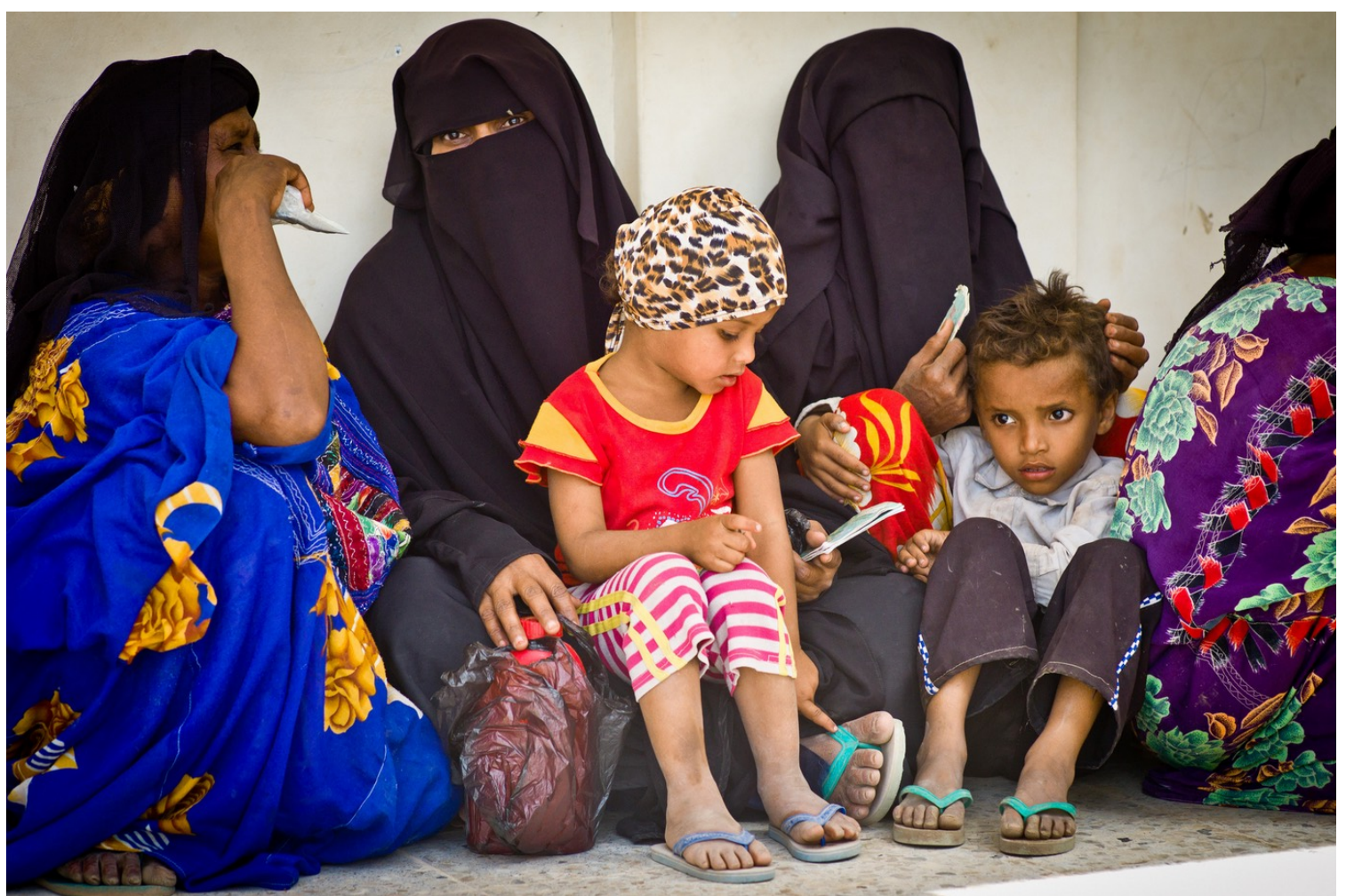

Women and children waiting for distribution of humanitarian aid by Oxfam in Al Hodeidah. @Wolfgang Gressmann/Oxfam 2012

\section{GENDER ROLES AND RELATIONS}

\section{PRE-CONFLICT}

Historically, women in Yemen have had much less power in society than men. Despite gains made during the National Dialogue Conference (NDC) process in 2014, women's political participation has been sidelined as a political issue in the wake of the current conflict. Before the current crisis, Yemen was ranked 142 out of 142 countries in the World Economic Forum's Global Gender Gap Index, a position it has held for almost a decade, and which reflects its severe, complex and diverse gender inequalities. ${ }^{30}$ Although the Government of Yemen has made efforts to improve the rights of women in Yemen - including via the formation of a Women's Development Strategy and a Women Health Development Strategy - many cultural and religious norms, along with poor enforcement of this legislation, have prevented Yemeni women from having equal rights to men. ${ }^{31}$

Women are traditionally the primary caregivers at the household level. Women and girls have primary responsibility for cooking, cleaning, collecting water and firewood, and childcare. They are also responsible for taking care of the elderly, the sick, and people with disabilities. In addition to these roles, women provide $60 \%$ of the labour in crop cultivation and more than $90 \%$ of the labour in tending livestock, while earning $30 \%$ less than men. ${ }^{32}$ When food is scarce, 
females are the first to eat less as a coping mechanism, even though they continue to carry out hard physical activities such as working in the fields. ${ }^{33}$

The heavy care burden that falls to women limits their ability to engage in paid work. For girls, this burden often means they are unable to attend school; among those who do attend, drop-out rates are high, with girls representing $63 \%$ of school drop-out children. ${ }^{34}$ Girls are the first to be withdrawn from school to save the family money or so they can enter into early marriage.

Gender roles that attribute time-consuming tasks to girls (for example, fetching water in rural areas) and a general lack of appreciation for girls' education also contribute to lower attendance rates. Girls also need more privacy in schools (latrines, etc.) and are less likely to attend if the facilities are inadequate, which is often the case. Control of ultra-religious groups over government institutions could complicate access to schools in some regions, especially for girls. ${ }^{35}$

\section{CONFLICT IMPACT}

During conflict, men and young boys are more likely to be killed or injured while fighting. This means that many women and girls are taking on roles that are normally the preserve of men. This is particularly difficult for women because of social exclusion and lack of mobility due to cultural norms, and limited access to resources. This was confirmed by focus group discussions. If women are unable to overcome cultural barriers to access essential humanitarian services and means of survival it leads to a heightened risk of exploitation and abuse, as well as increased vulnerability, particularly for female-headed households. ${ }^{36}$ The weakness of rule-of-law institutions and protection systems disproportionately affects women, boys, and girls, making them more vulnerable to grave violations of their rights, exposing them to exploitation and ensuring they face multiple barriers to justice. ${ }^{37}$

Figure 5: Percentage of male and female members of IDP households

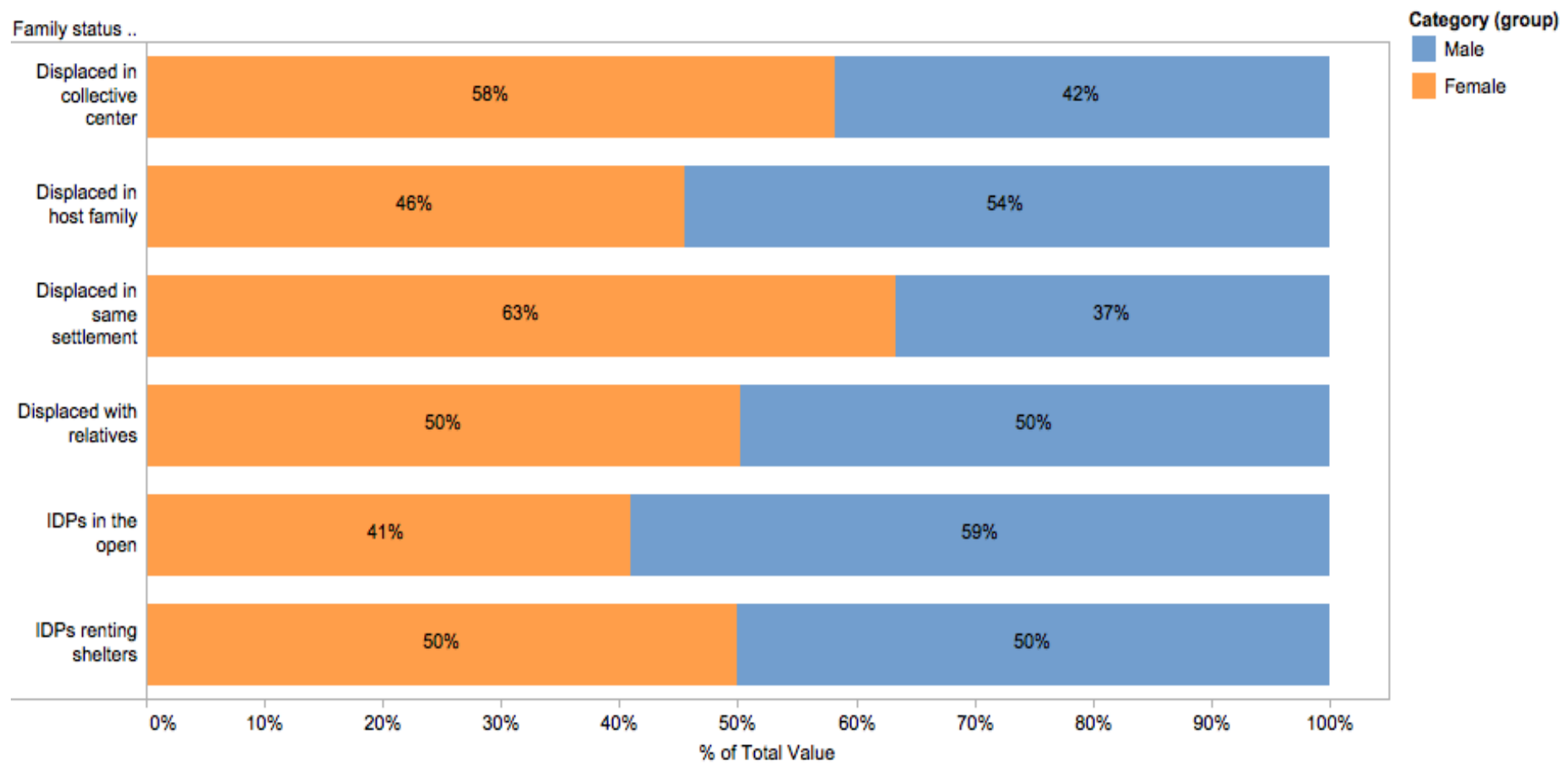

Source: Household interviews

Civilian men and boys can suffer humiliation and denigration at the hands of armed groups, as well as arbitrary detention and summary execution. Focus group participants reported an 
increasing trend of young men joining armed groups, either with the aim to provide an income for their families, or out of patriotism and feeling the need to contribute to resolving the current crisis. This trend is not limited to specific groups, and was reported in all four governorates, including in southern areas that are controlled by salafi jihadi groups. Young men joining armed groups receive salaries or financial support from the groups or their supporters (especially in the northern governorates), and have greater access to limited resources such as fuel or food. Focus group participants reported that households in the southern parts are often more hesitant to send their young men to fight with salafi groups. One woman stated: 'They come back as different men' - explaining that they were influenced by the ideology and often traumatized.

At the same time, participants reported that for men who stay at home, their limited ability to earn an income and their 'idleness' often become the cause of domestic conflict and violence. Related to this, interviewees reported increased conflict between husband and wife as a result of enhanced roles of female household members in earning income and managing the household, while men often see themselves as being forced to take on women's roles in the household, including collecting water, cooking and childcare. Participants in the focus group discussions reported that forms of violence by men at household level often include verbal abuse of women and physical abuse of children.

Nonetheless, focus group discussions and interviews with key informants also highlighted some positive changes in the roles and responsibilities of women and men as a direct consequence of the prolonged conflict, including changing perceptions of 'appropriate' behaviour or work for women and men. In a number of communities, focus group participants reported an increased appreciation of women's and men's roles, and an improved sense of how gender roles are mutually reliant. As one male participant in Hajjah stated: 'When we had to stay at home, we saw how difficult it was for our wives to take care of all the family issues, especially getting firewood and water.' More men are now taking on these roles which were previously done only by women. According to female household interview respondents in many locations, husband and wives used to 'quarrel a lot' before the conflict, especially when the men were working as daily labourers. 'Wives kept on pushing them to get more work to get more income.' Today, lack of income opportunities is recognized more as a general problem, and is not individualized to household level.

Focus group participants also reported that the conflict has reduced the impact of restrictive cultural norms and traditions around women's participation in community life and employment; there is also increased openness to women engaging in professions that used to be considered 'shameful' (such as butchers, barbers, or chicken sellers) and were associated only with marginalized groups. This has resulted in women becoming more engaged in managing family affairs and contributing to household income. As one focus group participant reported: 'It is no longer shameful for women to go to work or to seek food assistance from neighbours, or to borrow money.'

Household interviews found that important differences remain in gender roles and the involvement of female and male household members in daily tasks. On average, women spend 8.7 hours on household tasks compared to 2.8 hours for male household members. The main tasks women are engaged with are cooking (2.1 hours per day), housework and cleaning (2.0 hours) and childcare (1.9 hours). The main tasks within the family for men are childcare $(0.7$ hours per day), food purchase ( 0.6 hours) and healthcare of relatives ( 0.5 hours). 
Figure 6: Engagement of males and females in household tasks in hours per day

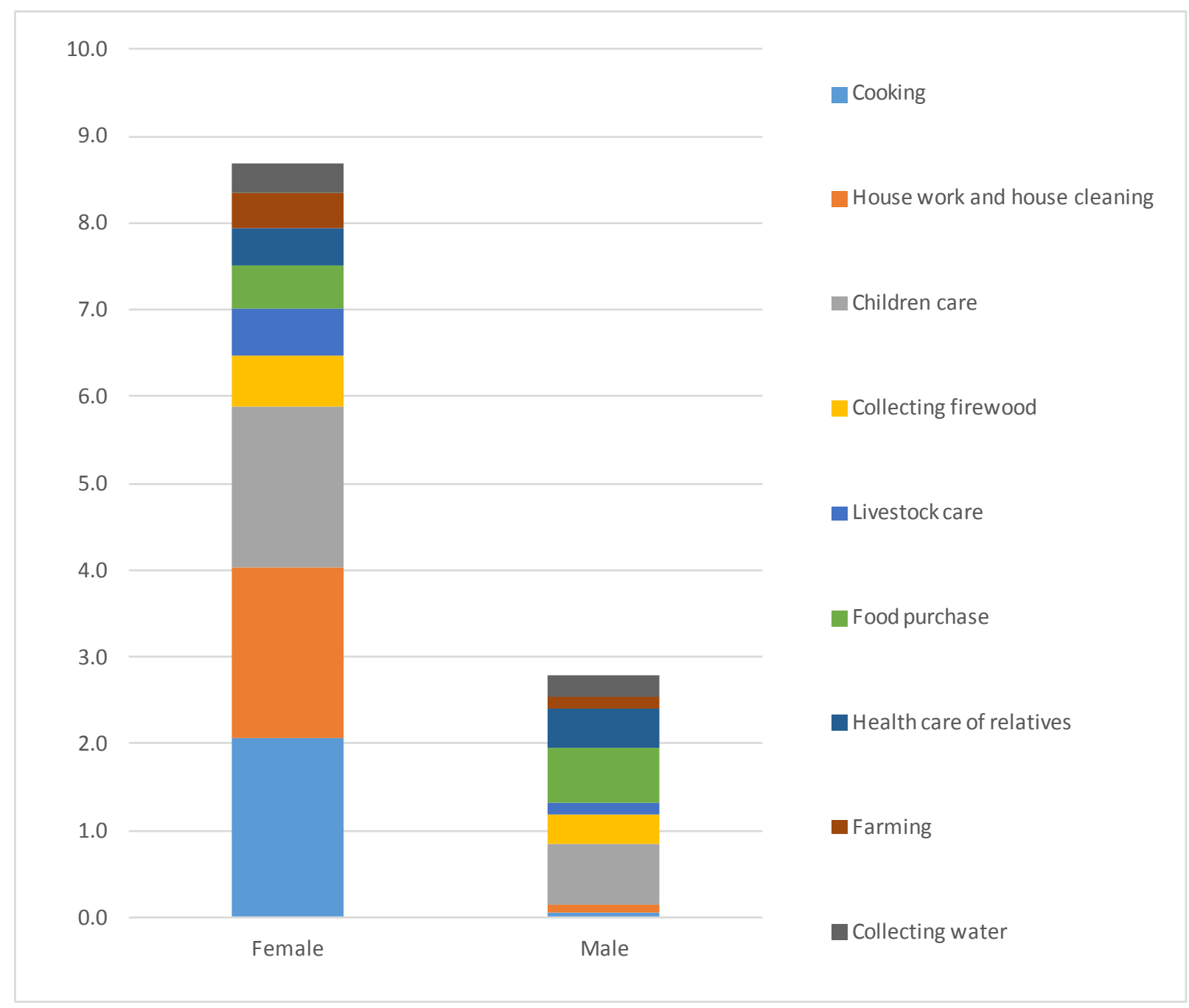

Source: Household interviews

Both men and women reported spending more time on household tasks compared to before the conflict. Female respondents reported spending more time collecting firewood (as many households are now using firewood as cooking fuel), cooking and childcare. Male respondents reported spending more time on collecting water and firewood, as well as on childcare. 
Figure 7: Hours spent on household tasks pre-crisis/today

Female

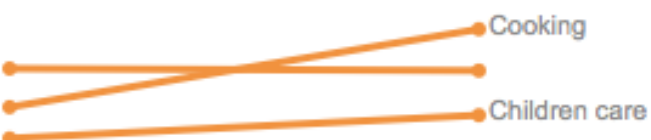

Male

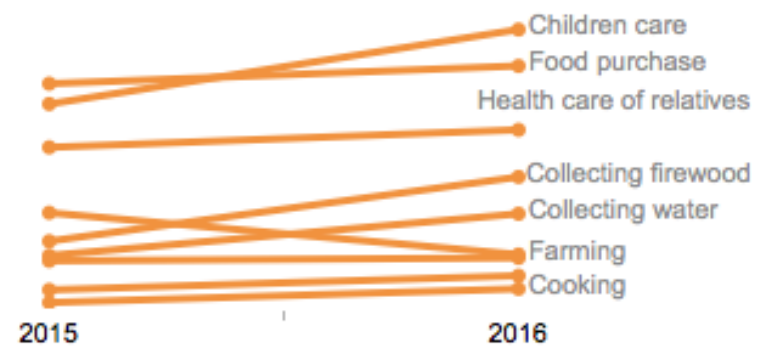

Source: Household interviews

With ongoing insecurity, collecting water and grazing livestock are more dangerous and are increasingly being carried out by men and boys in some locations, particularly in areas marked by the presence of armed groups, and especially among displaced populations and in rural areas. Female-only households and rural girls who are now living in urban host accommodation still carry out these tasks, placing them at risk of harassment and potential GBV. Women and children are also at risk of being injured by mines and unexploded ordinance while accessing water and sanitation facilities and services. ${ }^{38}$

\section{Case study: Ahmed's story}

I used to work in Taiz for a private telecommunications company. I lived with my family in my own home. We were happy with our simple life. One day I had an accident. At the beginning I was hoping to recover, but when the surgery failed that hope faded away. I became disabled.

The company paid me a little money as compensation. I spent this to open a small grocery store in one room of my house after I was trained to use a wheelchair. [The income from this] barely covered my family's food needs. We didn't expect the war, which worsened our already difficult life.

At the beginning of March last year, we were at home when rockets started to fall down from all directions. We didn't have a choice and left the house. There were four of us: my wife, me, my boy of ten and my girl of seven. We fled to our original village and lived in house that belongs to one of my relatives. My family and I used to get aid from relatives for a year. My children haven't been able go to school, which they loved. In addition, my wife lost her job in the city. We are unable to cover our children's needs. I became frustrated day and night. Under these circumstances my wife is responsible for the house and the decision making, dealing with my brothers and sisters who assist us.

(Ahmed, 36 years) 
The increased contribution of women to household income is leading to shifts in views held by women about joint ownership of household assets. As a trend, female respondents reported more 'joint ownership' with their spouse when it comes to livestock ( $17 \%$ when compared to male: $8 \%$ ), valuable furniture (34\%; male: $15 \%)$ or their house $(40 \%$; male: $16 \%)$. This observed trend is higher in rural settings than urban settings. According to key informants, the different views on ownership were based more on 'perception' than 'fact'. Key informants believe that this different perception of ownership is likely to cause increased conflict between spouses at household level.

\section{Figure 8: Ownership of household assets as reported by male and female respondents}

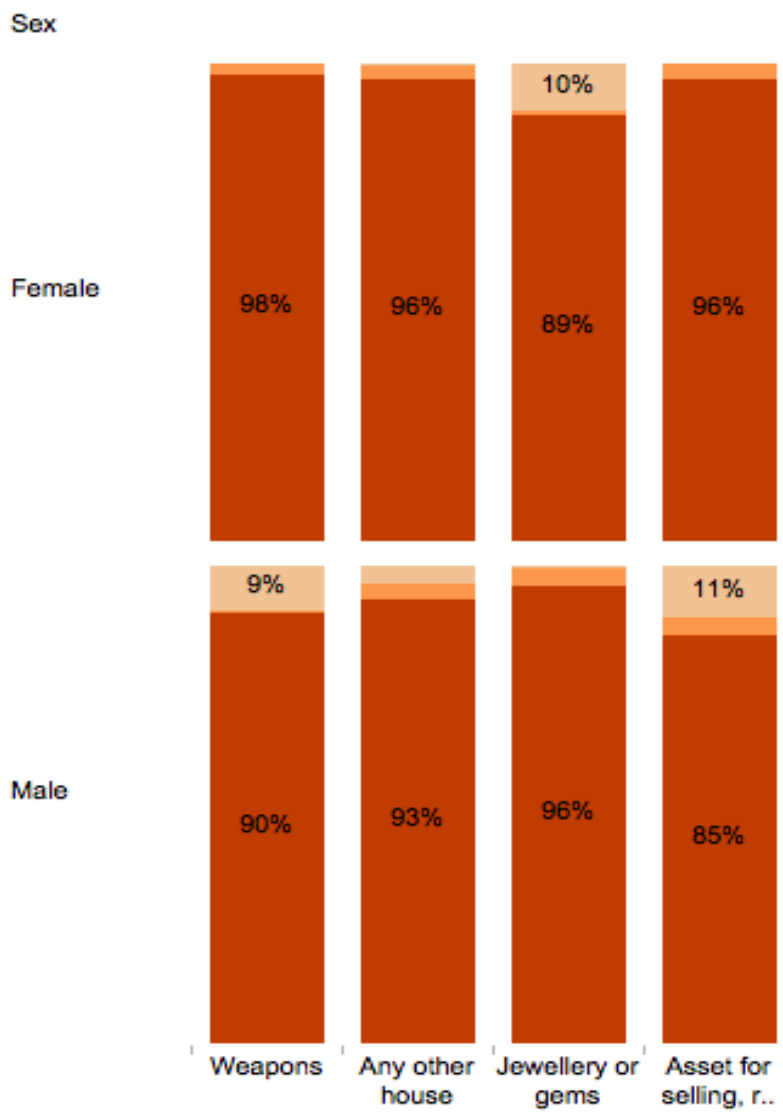

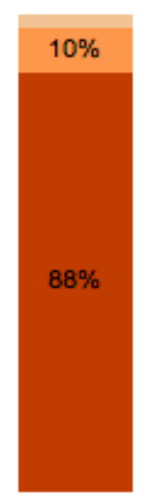
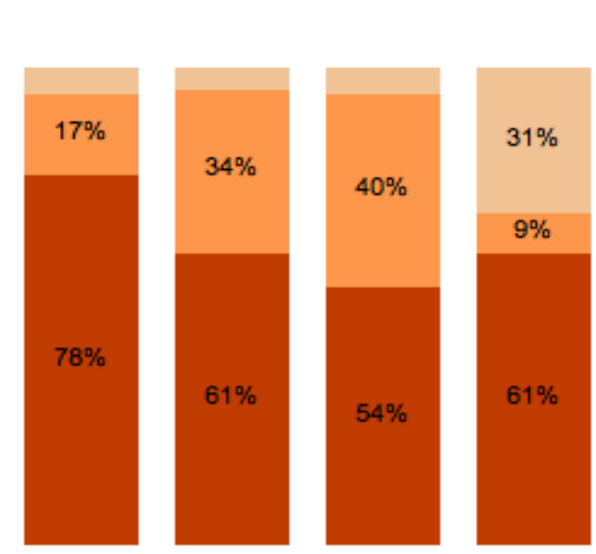

Variable
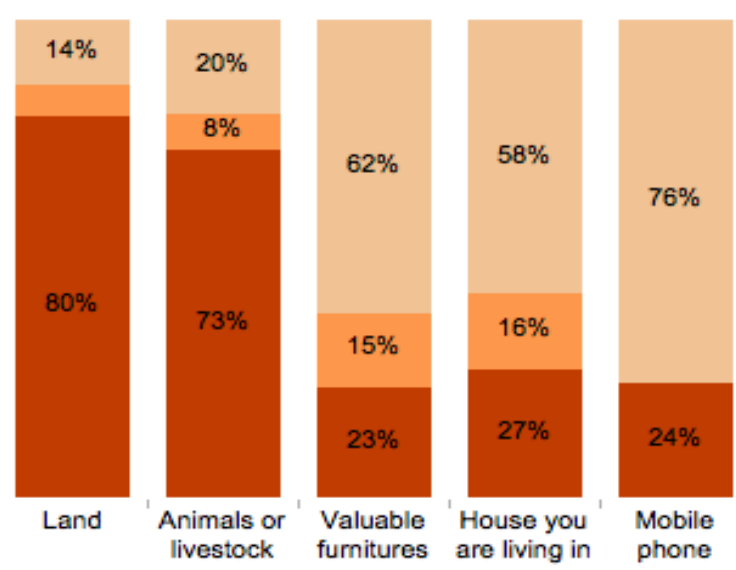

Source: Household interviews

There are indications that households have fewer assets now than before the conflict, suggesting households are selling assets as a consequence of the crisis. Of household respondents, $13 \%$ reported owning jewellery before the crisis, while only $8 \%$ reported owning it today. Similarly, $29 \%$ reported owning animals and livestock before the crisis, but only $25 \%$ today.

Participants in the focus group discussions reported that the experience of the prolonged conflict has led to an increase in the number of men who are married to more than one woman. An estimated $6-7 \%$ of wives in Yemen were married to polygamous husbands before the current conflict. ${ }^{39}$ Marriage is a common traditional and culturally accepted practice and coping mechanism, both for protection against harassment outside the extended family and to reduce economic pressure. As one female participant reported: 'The war offers chances for men to get married more easily than ever before. Dowry payments are less now, as parents are more determined to marry their girls.' In a focus group discussion with marginalized women, polygamy 
was indicated as a strategy by men to increase their income through begging conducted by multiple wives.

Many women in Yemen have lost access to family planning services, exposing them to potential unplanned pregnancies in perilous conditions. With the heightened risk of communicabledisease outbreaks, including of dengue fever, bloody diarrhoea and measles, it is essential that adequate and appropriate messaging for women and girls is made available - especially given the high levels of female illiteracy - to help them prevent infection, identify symptoms and seek treatment. ${ }^{40}$

Focus group participants reported that the economic hardship is not expected to improve after the conflict ends, and the increase in polygamy is expected to continue as a common coping mechanism, even in southern governorates where it used to be less common.

\title{
4 CAPACITIES AND VULNERABILITIES
}

\begin{abstract}
Case study: Suad's story
Most of the families in the village are fishermen, like my father used to be. My mother is taking care of the children. That was our life until the war. My father was out on the sea when we had to escape with only the clothes we were wearing and 4,000 Yemeni Rials. We were hosted by a family in Khaisah. We did not know what happened to my father.

Our host family didn't only save us, but also taught us how to continue living. They were not rich but they were able to sustain themselves because the wife made incenses and perfumes. When I saw that people were buying these products, I wanted to learn how to make them. The woman encouraged me and showed me how to mix and pack the products.
\end{abstract}

We returned to our village when the fighting stopped. My father also came back but he was wounded by shell fragments during the clashes in Dhobab district. An armed group had taken his boat. My father has become disabled and my mother is illiterate and unable to do any work outside of the house.

Somebody had to work and cover the daily expenses of our family. Their only hope was me. I had to work to protect my family and myself. I borrowed 5,000 Rials from my neighbour and started producing incenses and perfumes. It was like the first step in a thousand-mile journey. I started to make enough profit for me and family to live on. Then we started selling our products in the neighbouring areas. My family's income increased and our life became much better than before. We thank God and the family who took good care of us when we were displaced in Khaisah.

(Suad, 24 years) 


\section{CAPACITIES AND RESOURCES}

\section{Employment and income}

According to secondary data, some $10 \%$ of married women aged 15-49 were employed at some point before the 2015 conflict. There is substantial variation in women's employment status. Married women in Sana'a governorate are most likely to be currently employed (32\%), while those in Ibb governorate are the least likely (3\%). 'Ever-married' women with higher education are far more likely to be currently employed (43\%) than women who have less education $(8 \%) .{ }^{41}$ Of those, $44 \%$ did not receive any form of earnings for their work, especially in the agricultural sector. Younger women are more likely than older women not to be paid for their work. ${ }^{42}$ According to pre-crisis statistics, women earn substantially less than men $(1,751$ Rials compared to 6,343 Rials) ${ }^{43}$

Before the crisis, many women were involved in agricultural production - providing $60 \%$ of crop cultivation labour and $90 \%$ of livestock-tending labour. At the same time, less than $1 \%$ of agricultural land is owned by women. On average, female agricultural workers earned $30 \%$ less than men. ${ }^{44}$

At household level, $15 \%$ of the 544 interviewed households reported having no access to income from paid livelihoods. The percentage is highest in Hajjah (26\%) and Taiz (21\%), and the lowest in Aden (4\%) and Abyan (8\%), where the population has access to the profession of fishing. Male respondents reported this percentage of income higher compared to females, which could be an indication for some assessment bias. The main livelihoods differ between rural and urban settings and the four governorates, but with no large differences between female and male respondents. Daily labour is the main paid livelihood ( $41 \%)$, especially in urban settings, followed by jobs and paid employment. Fishing is an important source of income (only in Abyan and Aden), followed by small trade, livestock and farming.

Figure 9: Main type of livelihoods by governorate

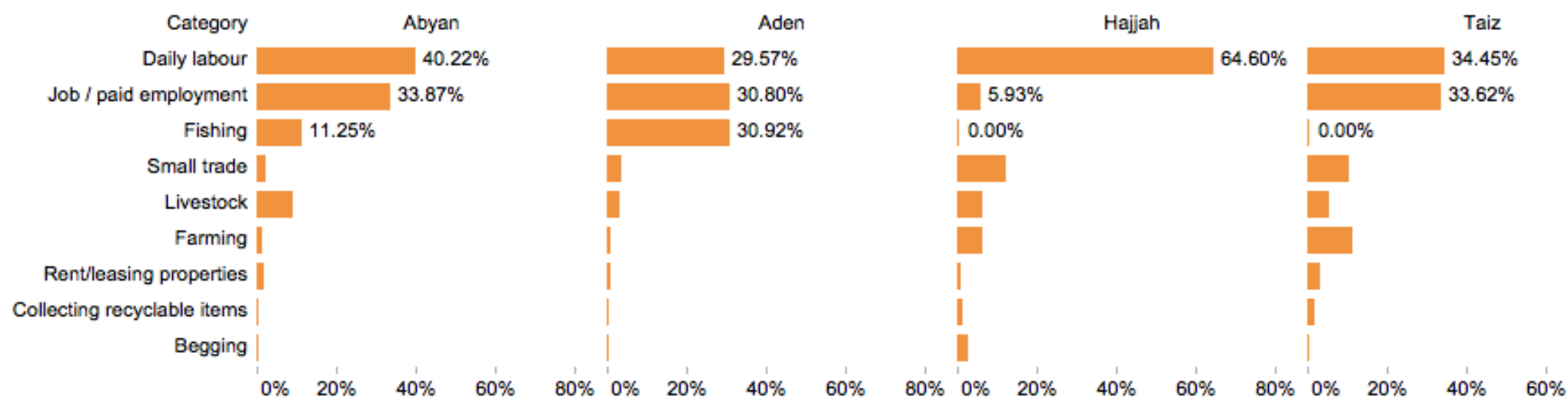

Source: Household interviews

A striking $92 \%$ of interviewed women reported having no regular personal monthly income. The percentage is highest in Aden (97.1\%) and lowest in Abyan (86.4\%). Only 26 out of the interviewed sample of 280 women reported a personal monthly income. This sample is not sufficient to determine average salary levels for women. Half of the women with an income only earn between 3,000 and 10,000 Rials per month (\$12-40). Women who earn more (up to $\$ 280$ per month) mainly reside in Abyan (where communities have access to fisheries). In comparison, $16 \%$ of male respondents declared having no personal monthly income. The average income of male respondents who receive a monthly income is 42,500 Rials per month (\$170). The average income of male household members corresponds with the declared family 
income, averaging at 42,500 Rials, with the largest proportion of households (17\%) earning an average of 30,000 Rials $(\$ 120)$ per month.

The vast majority of male respondents with an income reported sharing their entire income with the family. The percentage of male respondents that share only part of their income decreased from $8 \%$ pre-crisis to $2.4 \%$ today. Interestingly, female respondents with an income (note: only 26 out of 280 women) are more inclined to share only part of their income. Reasons for this include the need to maintain men's motivation to look for new jobs, as well as a belief that women in Yemen are more 'wise' in spending limited household resources, or more likely to save as a contingency against shocks. In the words of one female focus group participant: 'Women can keep feeding the whole family with a limited amount of money.'

Figure 10: Personal income interval by sex

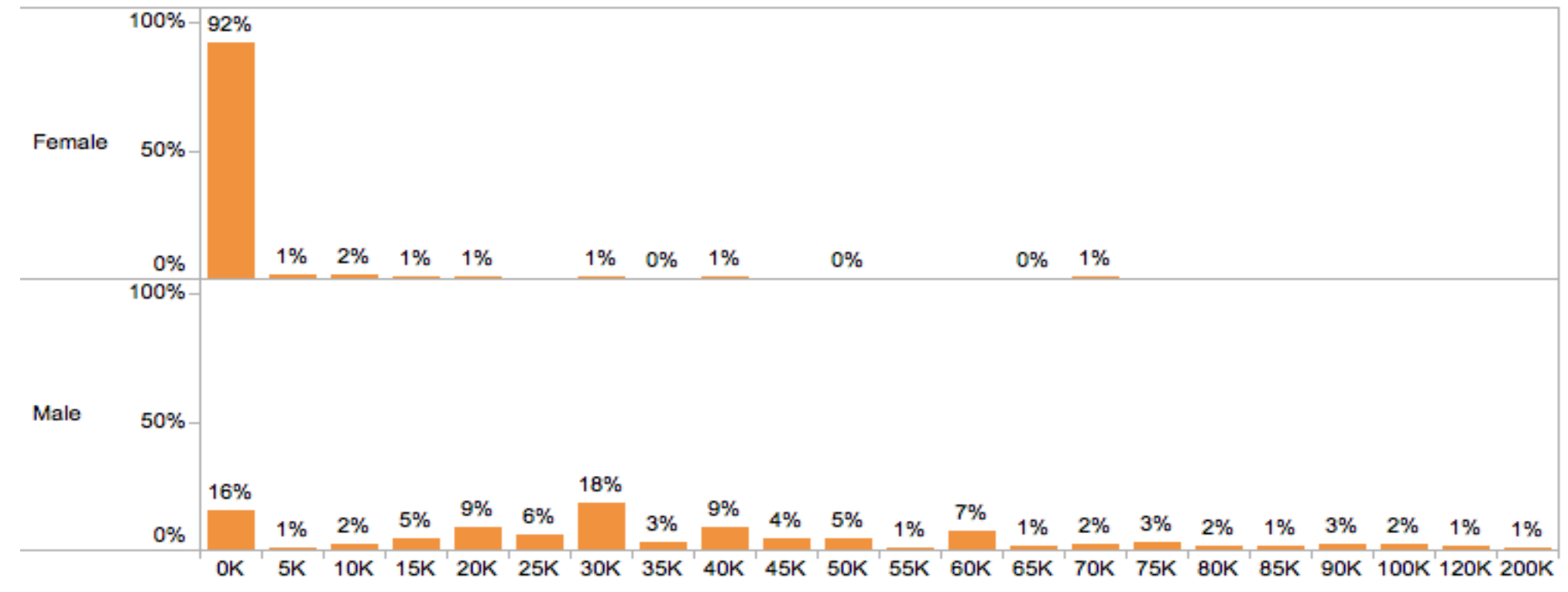

Source: Household interviews

Male and female household respondents reported that there have been changes in their main livelihoods since before the crisis and today. While women reported an increase in daily labour, male respondents reported increased importance of paid employment/jobs. According to key informants, this is again based more on perception than fact. Men often reported having relied on government subsidies and salaries before the crisis, ${ }^{45}$ which were supplemented by other jobs. The significance of fishing as a main source of income was reported in Abyan and Aden, while an increase in begging was reported, especially in Hajjah and Taiz; these are home to a high number of marginalized groups, for whom begging is traditionally a source of income. Many displaced households prefer not to reside in camps or collective accommodation because they are afraid of being stigmatized. They often resort to begging and sending their children to traffic points (to beg) as a means of livelihood, especially in less conservative urban host communities where they are not personally known. 
Figure 11: Main type of livelihoods pre-crisis/today

Female

1.4

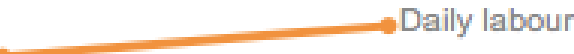

1.2

1.0

$0.8-$

8

0.6

0.4

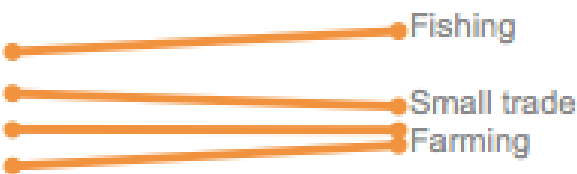

0.0

Begging

2015
Male

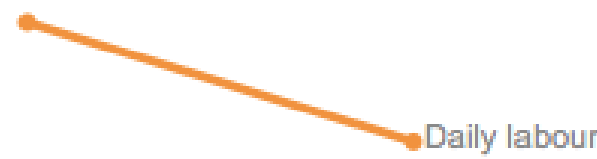

Job / paid employment
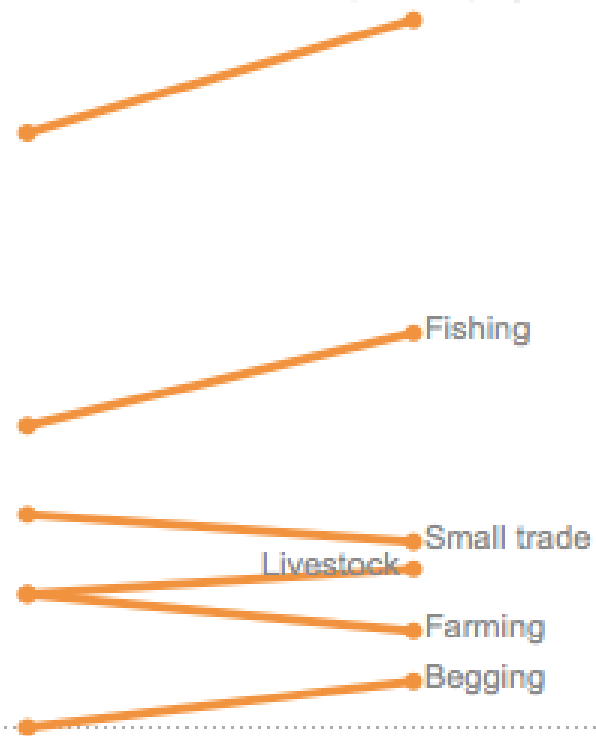

2015

2016

Source: Household interviews

At household level, a clear negative impact of the prolonged conflict on income levels was observed. This is most probably linked to the reported decline in working hours since the start of the conflict. The number of male workers that used to work from morning to evening dropped from $41 \%$ pre-crisis to $23 \%$ today, where males reported working only half a day, or less than 3 hours. The means of payment changed marginally, with a decrease in payment by cash (still the main way of getting paid) and a slight increase (from $1.4 \%$ to $4 \%$ ) of payment in-kind. As a consequence of the crisis, average monthly household incomes declined (including households with no income) from 49,110 Rials ( $\$ 197$ ) to 39,110 Rials (\$157) - a drop of more than $20 \%$. 
Figure 1: Personal and household income pre-crisis/today by sex

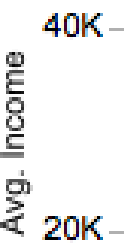
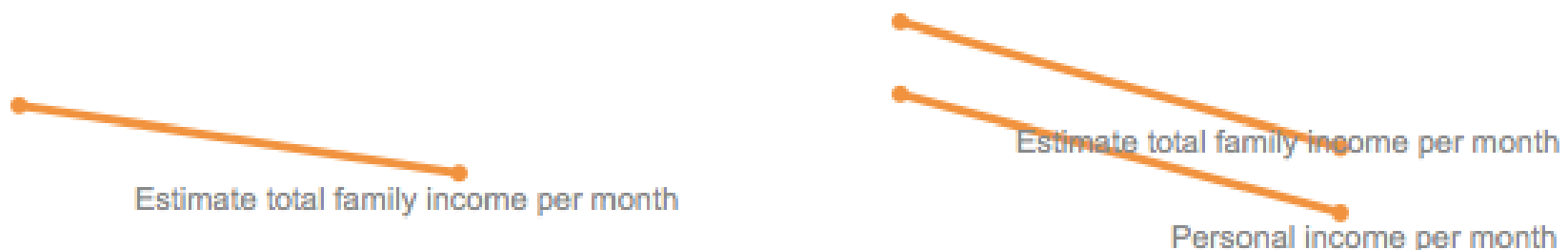

$\mathrm{OK}$

Personal income per month

Source: Household interviews

The majority of respondents $(65 \%)$ reported that they are receiving no additional income outside their main paid livelihoods. The percentage of households depending on additional income increased from $30.5 \%$ pre-crisis to $35.1 \%$ today. Looking at the sources of additional income, the percentage of households receiving humanitarian assistance has increased dramatically in comparison to assistance from relatives, retirement salary or remittances, when compared to pre-crisis levels. Conversely, the number of households that reported support from the Social Welfare Fund (SWF), the key social protection mechanism in Yemen, dropped from 25.3\% in 2015 to zero today. This confirms findings from the secondary data review: the SWF that used to cover almost $35 \%$ of the population reportedly has not been able to provide cash transfers since the first quarter of $2015 .{ }^{46}$

\section{Figure 13: Sources of additional income pre-crisis/today by sex}

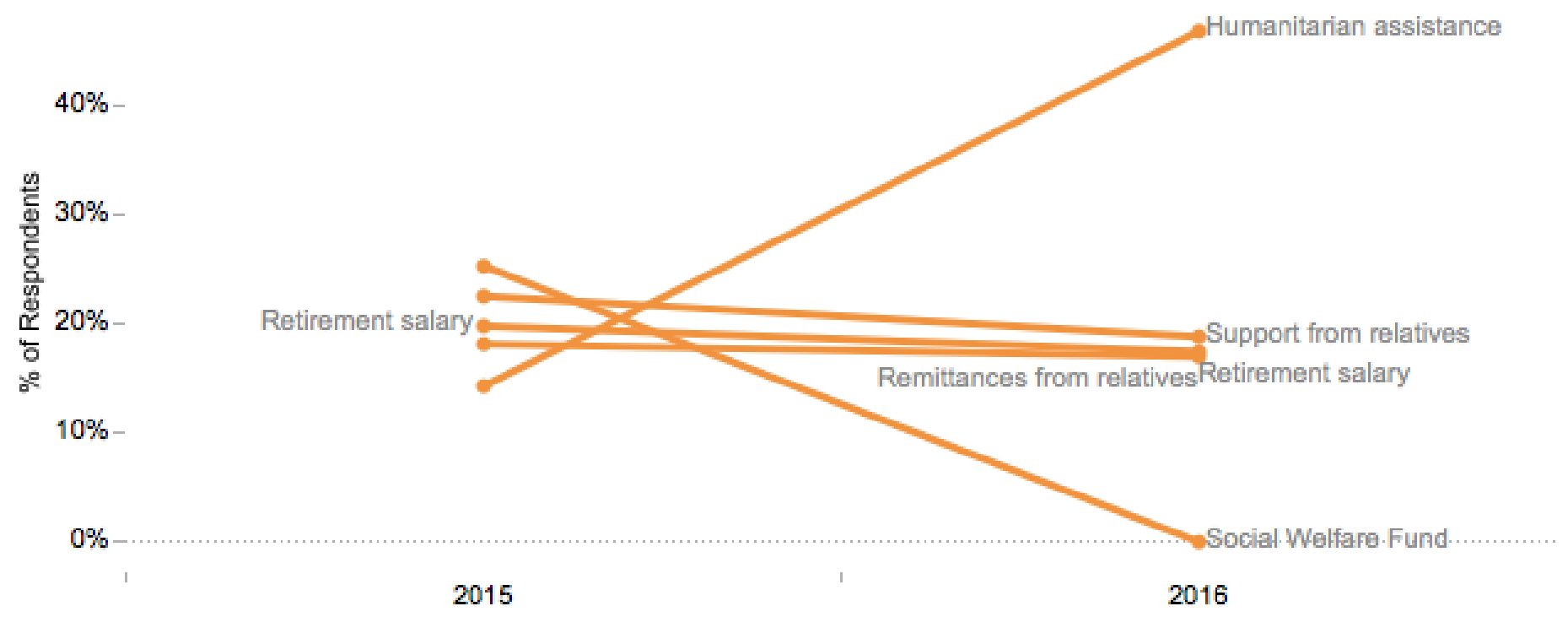

Source: Household interviews

This further exacerbates the fragile situation of most vulnerable households. Female focus group participants reported that the support from the SWF was generally used to pay back 
loans from relatives and shops, or from traditional women's groups (which are common among women in all sites and all social categories). Reduced income levels and lack of access to SWF support impacts severely on households' ability to pay back these loans, and accessing new loans becomes even more challenging. It is unclear whether humanitarian assistance is able to fill the gap left by the SWF.

Access to formal financial services is generally low in the assessed governorates, especially in rural areas. Female respondents in rural areas reported in $85 \%$ of cases that financial services are 'rarely' or 'never' accessible (male: $62 \%$ ). In urban areas, this percentage is significantly lower, with only $62 \%$ (females) and $0 \%$ (males) reporting financial services as never or rarely accessible. Widespread use of informal saving mechanisms before the conflict was reported by women in rural areas and poor communities during the assessment. Such practices among women have been reported in coastal areas including Tihama, Aden and parts of Abyan and Taiz. Larger risk-sharing schemes are more common in the northern governorates, where more advanced tribal networks exist, with wider coverage and more buy-in and support from communities.

Before the crisis, indigenous women's saving groups ('Hakbah') were described by focus group participants as very effective in supporting vulnerable community members in emergencies (hospital visits, deaths) or marriages, becoming de-facto health, life, and accident insurance schemes. However, female focus group participants indicated that the limited amounts they used to save in groups became insufficient to meet the unexpected demands caused by the crisis. Many of these solidarity groups had to stop working or limit their activity to providing support only in extreme emergencies, especially in Abyan and Aden, while their functionality remains higher in Hajjah and Taiz.

Buying on credit from (female) door-to-door traders has become inaccessible in many of the visited areas, as many traders have had to stop their small businesses because they could no longer get goods on credit from private suppliers, combined with the difficulty of receiving payment at household level. 'Social guarantees' (i.e. when one well-known person introduces people who need goods or credit to related suppliers, and ensures repayment if not fulfilled) remains a common practice for accessing credit from shops.

\section{Community governance and protection}

At household level, perceptions held by female and male respondents about where community members can ask for help when they have been victims of violence has changed as a consequence of the conflict. Male and female respondents reported a decrease in the importance of formal protection mechanisms, in particular a sharply reduced role of police (especially in the perceptions of male respondents), while the perceived importance of informal protection service providers increased, especially that of community leaders, religious leaders and family members (the latter mainly for female respondents).

Interestingly, and while both female and male respondents reported that sheiks remain the main authority for addressing community protection concerns, female respondents reported a decreased role of sheiks when compared to the pre-crisis situation, while male respondents see an increase - possibly as a substitute for the less functional police capacities today. According to a pre-crisis report, while both men and women can access tribal actors, women face higher barriers to access and expressed a preference for approaching the wives of senior and influential members as a first point of contact. ${ }^{47}$ 


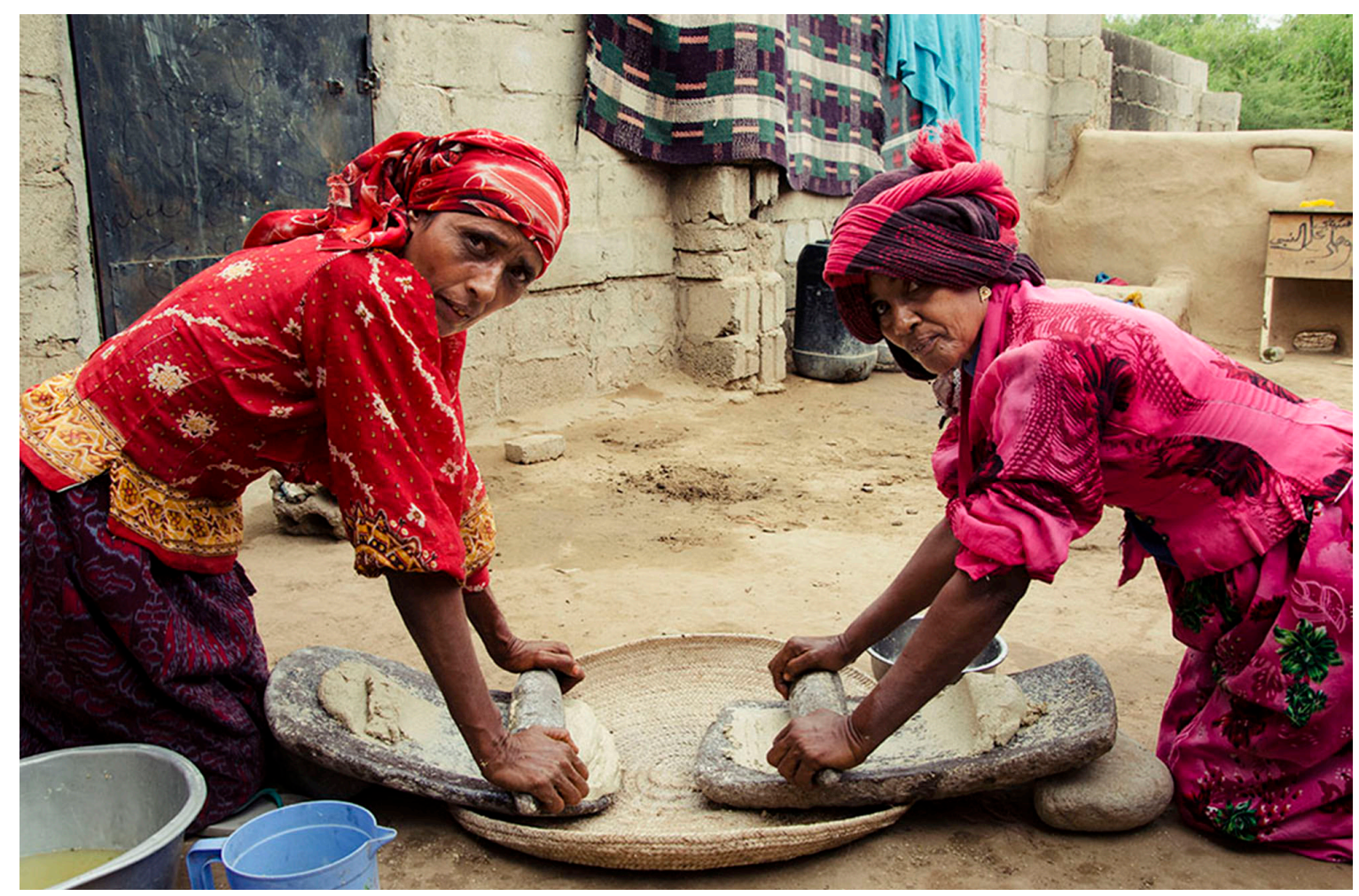

Women baking bread in a village in Taiz. @Thana Faroq/Oxfam, 2014

\section{MAIN VULNERABILITIES}

Women in Yemen face pervasive discrimination in both law and practice as a result of society's prescriptive gender constructs and norms. Women have limited access to political participation and representation, economic opportunities, educational opportunities and access to healthcare. Before the current conflict, gender-based violence (GBV) reportedly constituted a serious problem in Yemen. ${ }^{48} \mathrm{GBV}$ before the conflict included forced marriage, early marriage, exchange marriage, polygamy, female genital mutilation, denial of inheritance and restrictions to mobility. ${ }^{49}$ Additionally, $90 \%$ of women faced sexual harassment on the street. ${ }^{50}$ The lack of specific legislation, low confidence in the police, and social acceptance all contributed to this. In a pre-conflict survey by the Ministry of Public Health, half of all interviewed women believed that a husband is justified in beating his wife. ${ }^{51}$

According to focus group discussions, the psychological impact of the conflict affects all household members, irrespective of gender, age or displacement status. Women focus group participants reported psychological distress caused by violence, fear for their children and family members (including men), and fear of arrest or detention by armed groups. With regard to men, psychological stress was attributed to loss of livelihoods, restricted mobility, and being forced to perform 'women-specific roles' which reportedly often leads to increased levels of domestic violence.

As is the case in other conflicts around the world, in Yemen the escalation of the conflict and increase in displacement has increased the risks and incidence of GBV, including sexual abuse. ${ }^{52} \mathrm{OCHA}$ also noted a $70 \%$ increase of GBV incidents between March and September 2015. These included sexual violence, domestic violence, early marriage and trading sex to meet basic survival needs. Recent data estimates that 52,000 women are likely to suffer from such incidents, and require responsive critical medical care as well as immediate and long-term psychosocial support. The lack of such services, as well as a lack of safe refuges for victims of abuse, compounds the problem, as victims may face stigma and rejection from their families and communities. Cultural norms and stigma related to sexual violence further discourage survivors from reporting such crimes and from seeking necessary medical and psychosocial 
services. ${ }^{53}$ IDPs and host communities are especially at risk, and displaced children and children who have been separated from their families are particularly vulnerable. ${ }^{54}$

Child marriage is a pre-existing problem, with $52 \%$ of Yemeni girls getting married before the age of 18 , including $14 \%$ before the age of 15 . However, the trend is reportedly increasing as families use it as a coping mechanism during the ongoing crisis and as a means to access dowry payments. ${ }^{55}$ An IDP assessment in Taiz revealed that $8 \%$ of girls aged $12-17$ were pregnant, indicating a prevalence of early marriage. ${ }^{56}$

The majority of victims of GBV are women and girls, although men and boys are also affected. CARE reports accounts of sexual violence by armed actors against men and boys as a form of torture and when captured. ${ }^{57}$ During this assessment, one case was reported by household respondents (Abyan). Such cases are usually not reported for fear of putting the reputation of the entire family at risk, especially in the northern governorates.

Young men and women interviewed reported frequent feelings of frustration and fear, being forced to contribute to family income by selling qat or working as day labourers, with limited opportunities to improve their income or to study, and often feeling pressured by parties to the conflict and the media to partake in the conflict. For girls, the most-reported reasons for psychological distress were: feelings of helplessness caused by their inability to change or influence their situation, displacement, being forced to work, and being denied access to school. Some focus group participants reported forced and early marriage of underage girls. Others reported harassment in public places, especially of displaced women and girls, who are reportedly more likely to experience GBV. This is particularly due to the lack of privacy and security in IDP shelters, and to the extremely low degree of power and influence displaced women command economically, socially and politically.

When asked about the main challenges households are facing today, both female and male respondents reported similar priority concerns. The main worry is the lack of income to meet basic needs (37\%), followed by difficulties finding employment (31\%) and the inability 'to move around safely' (16\%). At household level, $74 \%$ of respondents reported an increase in security concerns for women and girls since the beginning of the crisis in $2015.84 .6 \%$ of female and $62.5 \%$ of male respondents reported such an increase.

Figure 14: Main challenges today

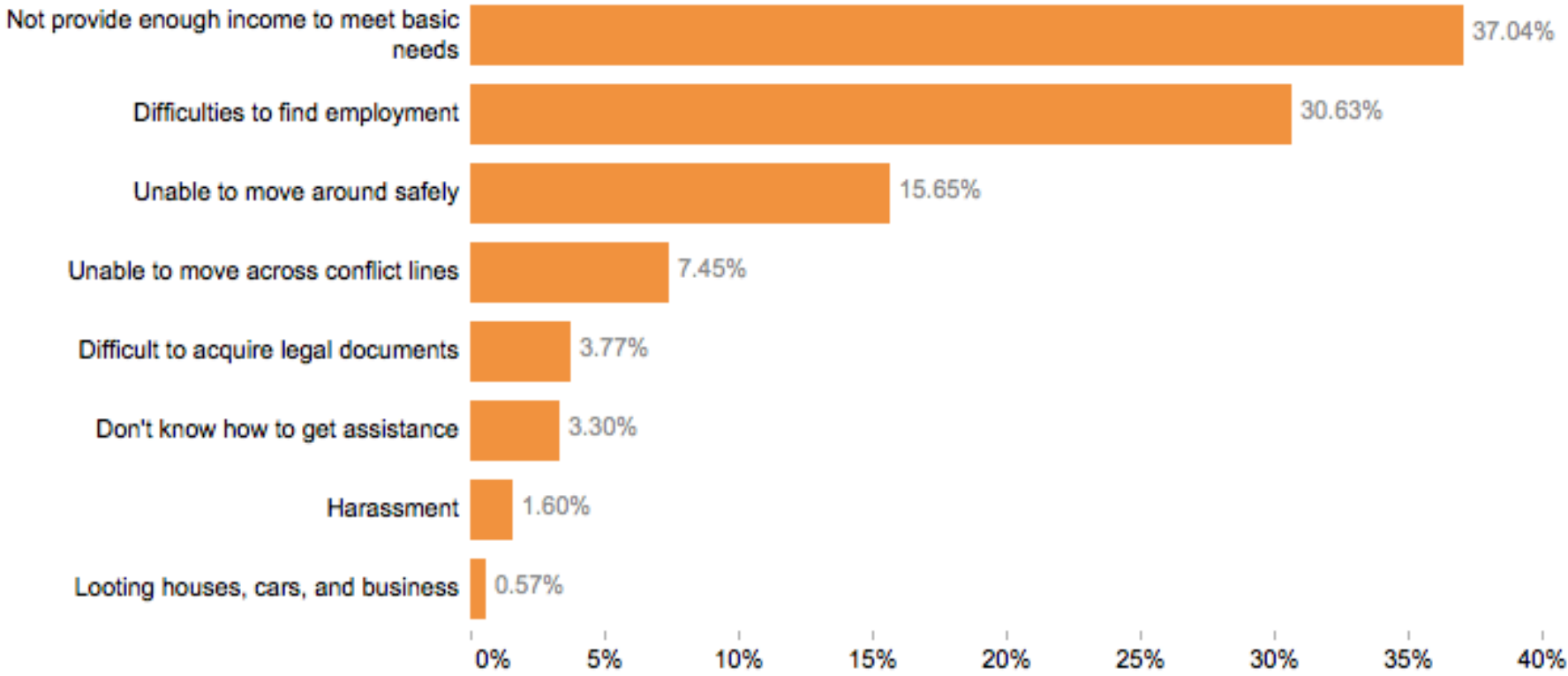


The perception of these risks differs between the four governorates. The main threat to women's and girls' safety in Hajjah and Taiz is the risk of airstrikes (according to $51 \%$ and $36 \%$ of respondents respectively), while the risk of 'kidnapping' is more prominent in Abyan (24.4\%) and Aden (17\%). When asked about the risk of kidnapping of females, focus group participants reported that this is usually linked to marriage without parental consent. One participant in Abyan reported: 'There was this young man who was close to AQAP. He wanted to marry a girl. Her parents did not approve, but he just took her and married her.' Of note in this context is that young males are attempting to become more powerful when they join armed groups, behaving in ways that would not have been culturally acceptable before the conflict.

\section{Figure 15: Main security risks for women and girls today by governorate}
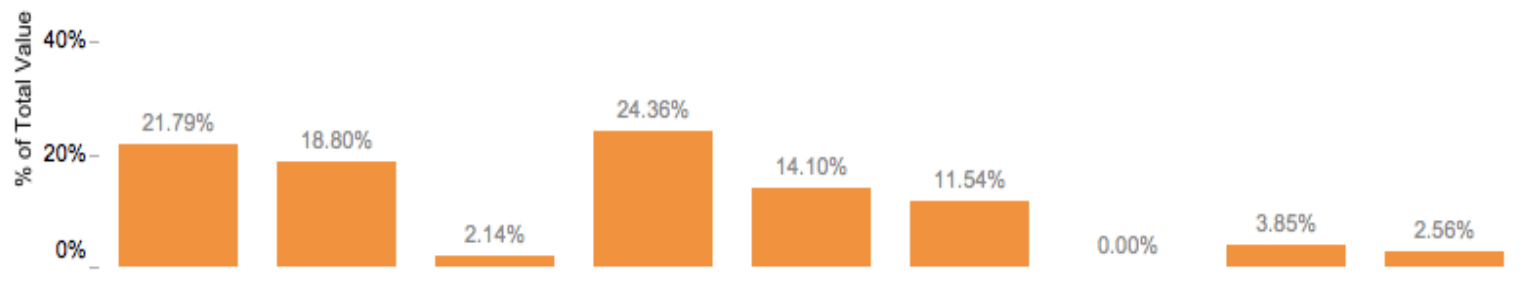

㠃 $40 \%$ -
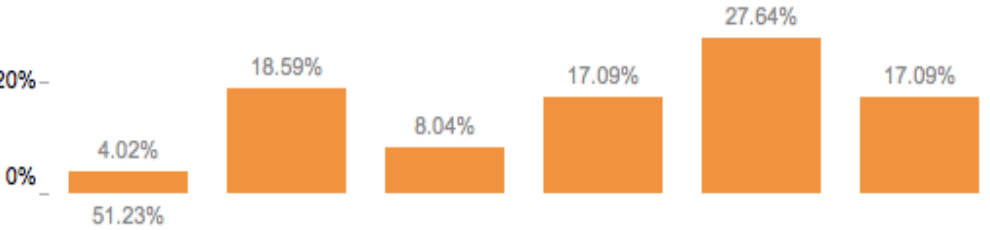

$0.00 \%$
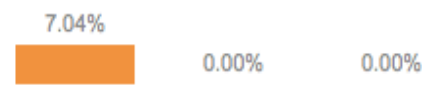

$0.50 \%$
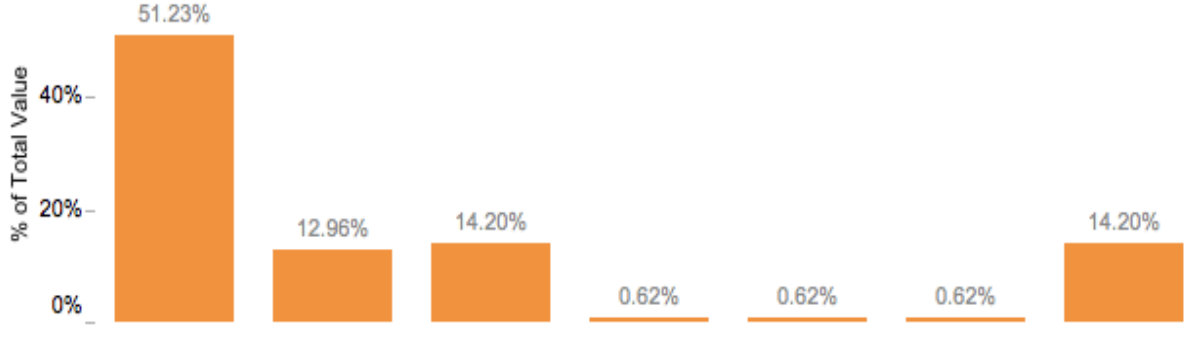

$0.00 \%$
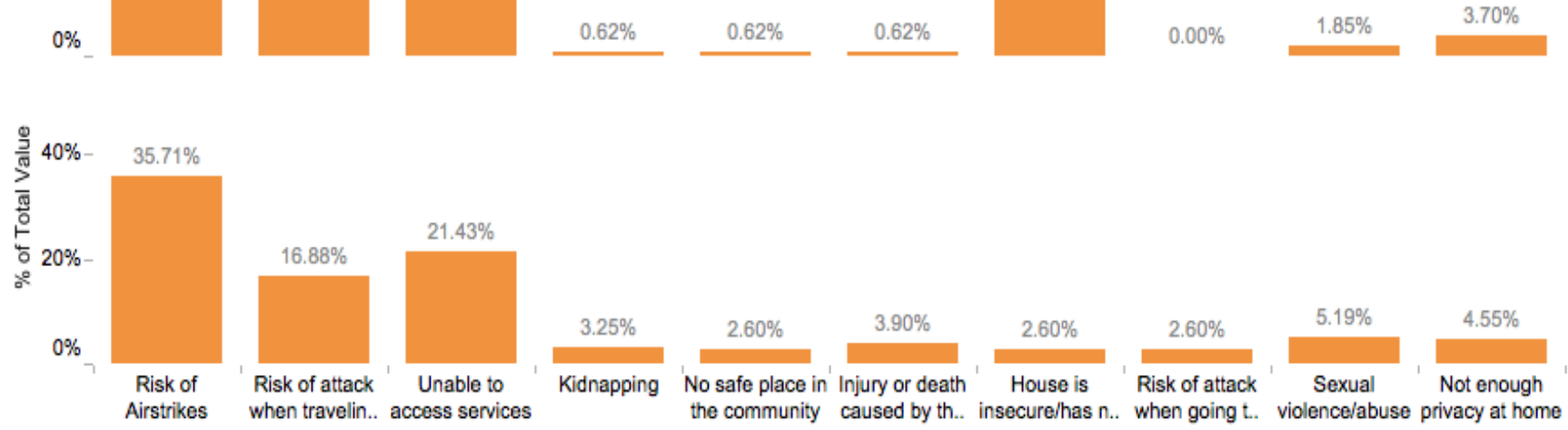

$\frac{1.30 \%}{\text { Being forced to }}$

Source: Household interviews

The risk of sexual violence against women and girls is considered the highest in Taiz (by $5.2 \%$ of household respondents, see Figure 15 above). This is explained by the large presence of marginalized groups (also represented in the sample for this assessment). One female participant of a focus group discussion with marginalized groups in Taiz reported: 'At checkpoints, our women get harassed by armed men on every side of the conflict. This is only because we are black.'

$79 \%$ of household respondents also reported an increase in security concerns for men and boys since the beginning of the crisis: $91 \%$ of female and $66.3 \%$ of male respondents reported such an increased risk for men and boys. The main difference in risks for men and boys, compared to 
those for women and girls, is recruitment/coercion by armed forces, especially in Abyan ( $23 \%$ of respondents) and Aden (19\%). Of note is the reported risk of sexual violence against men and boys in Abyan ( $2 \%$ of respondents).

\section{Case study: Ammar's story}

I have seven boys and girls. The oldest is in his twenties, the youngest is only six months old. We used to live in our house in the city of Taiz. I used to work as a bus driver. I covered all my family's expenses. Our life was normal, until the war started.

One day while we were all at home, we heard a loud explosion directly in front of our house. I looked outside the window, I didn't see anything and I was sure that the explosion had happened further away. Then I heard someone yelling my name. I opened the window and my heart was beating heavily. When the man saw me he said: 'Ammar the bus is gone, the bus is gone.' I ran out and my entire family followed me. We saw that the bus had been totally destroyed by a rocket.

Suddenly there was another loud explosion. My family and I ran back to our house. Where our house used to be, a column of smoke went up to the sky. It looked like a huge chimney. The second rocket had destroyed one room and the roof, and all the doors and windows were gone. I found myself like a blind man in the street. I had no bus and no house any more. The only consolation was that the second rocket didn't kill us, either by chance or by the grace of Allah.

I brought my family to my father's house, and returned to my house to investigate the damage. It was totally destroyed. A month later I gathered my strength and decided to restore my house in order to return with my family. I started rebuilding with a small amount of money. It was not enough, but at least I started.

Then another rocket killed my neighbour and destroyed his house. This was like a last warning. I decided to evacuate my family to a safer place. I sold my wife's jewellery and moved away. Now we have been in Batra Taiziyah area for six months. Some of my friends are living here. They welcomed me and my family for two weeks, despite their own difficulties. Then we found a temporary shelter at an unused health centre, but finding a job here or anywhere else is impossible.

My wife is now gathering firewood, collecting water and cooking whatever we have, in addition to taking care of the children, while I go searching for work or humanitarian aid. I can't travel far away looking for work because I don't want to leave my family alone.

(Ammar, 44 years) 


\section{PARTICIPATION IN DECISION MAKING}

\section{BEFORE THE CONFLICT}

Although women in Yemen have considerable productive and reproductive roles and responsibilities, they have traditionally had limited participation in society and a lower social status than men. Men have always been the primary decision makers both inside and outside of the household. ${ }^{58}$ Some progress had been made since 2011 in terms of women's participation in public life, but the risk of backsliding on this is extremely high. ${ }^{59}$

The 2011 Uprising challenged the norm of women's limited participation. Women were at the heart of the 2011 protests where they actively participated in demanding a better political life and livelihood opportunities. ${ }^{60}$ They represented more than one-quarter of participants in the National Dialogue Conference (NDC) in 2014. ${ }^{61}$ Through the NDC, women were able to achieve important agreements - including the $30 \%$ quota for women's political participation and a law to increase the age of marriage to 18 years - to form part of the new constitution. Overall, there were more than 173 articles and outcomes related to women. ${ }^{62}$

During the NDC, traditional actors and fundamental religious movements opposed demands by women and youth that challenged cultural practices and historical narratives. Gender issues and women's rights not only proved to be highly contentious issues in discussions, but women delegates were also in many cases publicly threatened for participating, and were even physically attacked. There are reports about female delegates being singled out by name and in pictures on the internet, and being called 'dishonourable' for going to dialogue meetings unaccompanied and at night. To counter those dynamics, women's human rights organizations, such as the Sisters Arab Forum for Human Rights and the UN Special Adviser and his team, increased their efforts to support and encourage women to participate and raise issues they cared about. Importantly, there were also several NGOs that supported the women by facilitating workshops and providing training sessions. ${ }^{63}$

At community level, a pre-crisis report recognized that a growing number of women in Yemen had engaged in civil society organizations or partisan and political frameworks. These groups and networks aimed to find safer environments to help women enter a public life that was dominated by and largely restricted to men, who were considered the source of 'hamiyah' (protection) in intercommunity relations. ${ }^{64}$

At the household level, some women are more likely than others to be involved in decision making. Older women, employed women, women living in urban areas and those who have more education are more likely to make decisions for themselves. Married women are as likely to say that decisions about women's own healthcare and about major household purchases are made jointly by the husband and wife as they are to say that such decisions are made mainly by the husband alone. $8-9 \%$ of married women say they make these decisions themselves. ${ }^{65}$

Women in Sana'a city and Aden governorate are most likely to participate in making household decisions. ${ }^{66}$

There is a difference in control over women's cash earnings by urban/rural setting: $57 \%$ of urban and $49 \%$ of rural women mainly decide how to spend their earnings. Women with no education are slightly less likely than women with any education to decide themselves how to spend their earnings. ${ }^{67}$

'When a woman works and brings money for the family, she has more power over family decisions. But the man feels humiliated and stays quiet in the house.'

(Female focus group participant - Taiz) 


\section{IMPACT OF THE CONFLICT}

Despite Yemeni women's demands and the UN's calls for women's participation, key warring parties have blocked women from travelling to peace talks. The UN has not called for inclusion of an independent delegation of women ${ }^{68}$ In response, around 50 Yemeni women regrouped in October 2015 to form the Yemeni Women Pact for Peace and Security. This brings Yemeni women leaders together to improve women's inclusion in peace-building processes and security. The Pact is facilitated by UN Women and has officially met with the UN Special Envoy twice since its establishment. The Pact is currently focusing on an initiative to build trust between parties to the conflict. ${ }^{69}$

The environment in some areas limits the participation of women and youth in humanitarian processes and systems (needs assessments, capacity-building activities and community committees), which affects the quality and outcome of the assistance provided. ${ }^{70}$

At community level, spaces and forums (formal and informal) used to make decisions (including traditional legal decisions) by communities include:

- Local authorities and service management committees: Pre-conflict, the majority of community decisions were made by local government authorities, such as managers of public service programmes. Men dominated these spaces and women's participation was limited, especially in the northern governorates. These structures witnessed major change as a result of the crisis. Some organizations maintained their capacity due to their affiliation to the party in control of the area. As a general trend, the role of woman in these remaining structures has declined further. According to key informants, these offices and committees are now entirely dominated by males.

- Sheikhs and tribal leaders are another set of important actors in communal decision making, with jurisdiction at the sub-district level. These are mostly men, but occasionally female sheiks are selected by the community. Furthermore, wives of sheiks or community leaders are reportedly a traditional route of referral for local women to these decision-making structures.

- Powerful individuals including high-ranking officials with extensive networks, as well as cultural and academic members of the community, religious leaders and businessmen. Women's engagement with these decision makers is reportedly limited to charitable programmes.

- Development and charitable societies: These are characterized by women's leadership, particularly in rural development and women-related activities. The majority of such societies in the northern governorates stopped their activities as a direct consequence of the conflict, while the number of societies in Aden and Abyan increased as a result of enhanced external funding of humanitarian assistance activities. Women are often involved in the management of aid programmes and volunteer work initiatives.

- Community and traditional leaders: Especially in rural areas, male and female community and traditional leaders were relatively active before the crisis. Their decision-making power is considerably reduced now, except for those who are affiliated to the conflict party in control of the area.

- Armed groups existed before, but had no formal decision-making authority at community level. When the conflict started, their role as a source of decision making at the community level increased substantially in all four assessed governorates. These groups are exclusively run by men.

- Community committees: Often supported by INGOs, these committees have formed in some communities as a result of the conflict to provide health services, protection services or humanitarian aid. Where they exist (especially in Aden, Abyan and Taiz) some women participate, especially in the delivery of women-specific services. Today, these INGO- 
supported structures are the main channels for decision making with the participation of women.

Based on the household survey for this assessment, female and male respondents confirm the described declining role of formal structures (e.g. local government) in community decision making. Male respondents reported a sharper decline in the importance of local government as community decision makers, compared to female respondents. They see an increasing role for sheiks and tribal leaders, while female respondents reported a decreasing role (although for both male and female respondents, sheikhs and tribal leaders remain the main decision makers at community level). Only a small number of respondents confirmed the presence of women's committees or other community-based organizations in community decision making, both before the crisis and today. Aside from conflict resolution and lobbying for services, the capacity of informal actors to assist communities is limited. ${ }^{71}$

Figure 16: Key community decision makers pre-crisis/today by sex

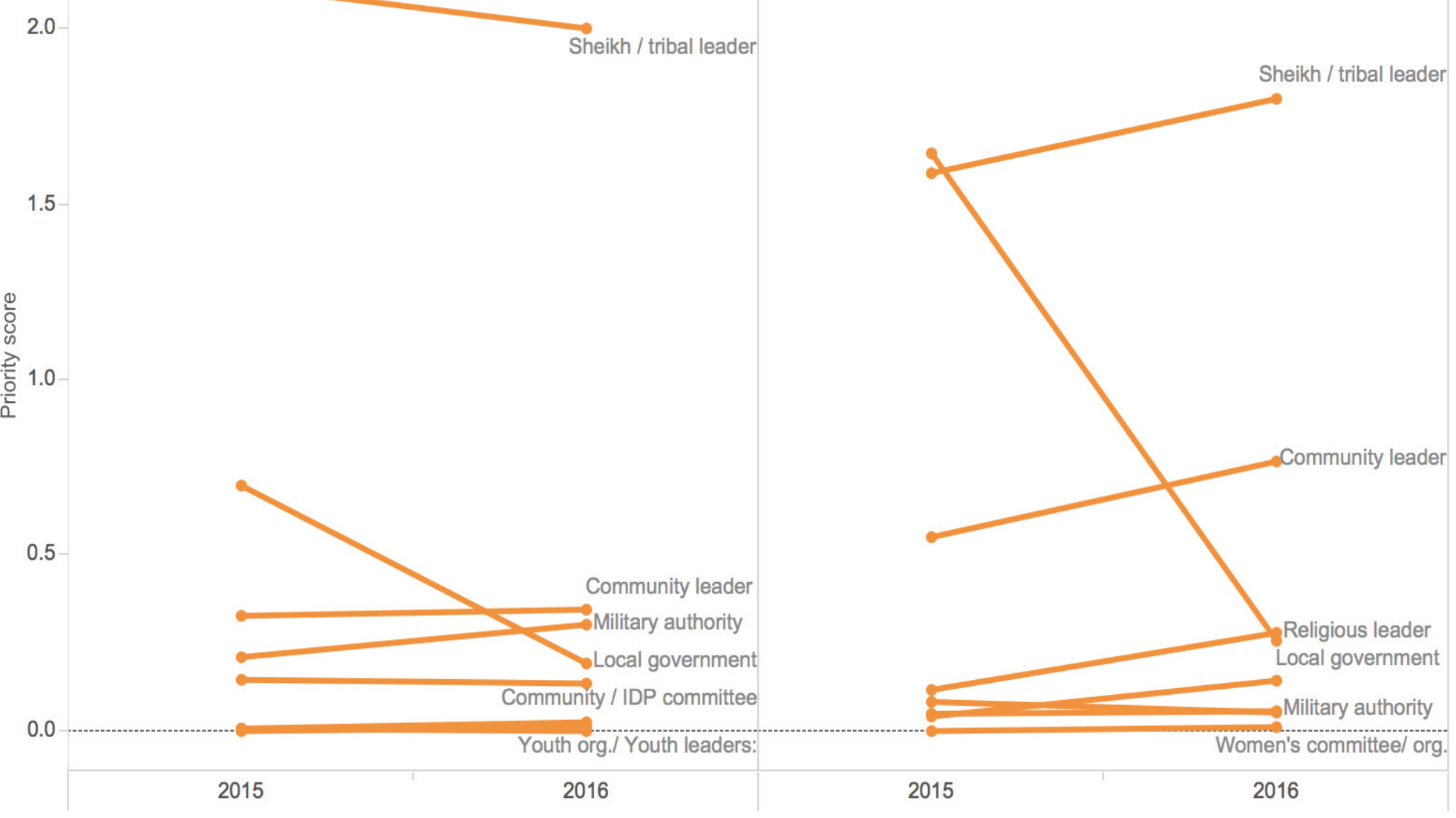

Source: Household interviews

Some participants in the focus group discussions reported that they go directly to armed groups to help them solve their disputes. Female focus group participants reported a preference for bringing their concerns to community leaders and committees, particularly with regard to their right to access humanitarian aid. Taking these findings into account, it does not come as a surprise that the overall level of engagement of household respondents in community decision making and social activities is low - both before the conflict and today. Participation in community decision making and in social activities has increased, however, for both male and female household respondents. This reflects increased engagement in the distribution of aid and outreach as a result of interventions by INGOs and the above-noted emergence of community committees in some areas. Focus group participants also reported women's 
engagement as volunteers supporting armed groups (especially in Aden and Taiz), especially when their family members and relatives are active in these groups.

Figure 17: Involvement in community decision making and social activities precrisis/today by sex

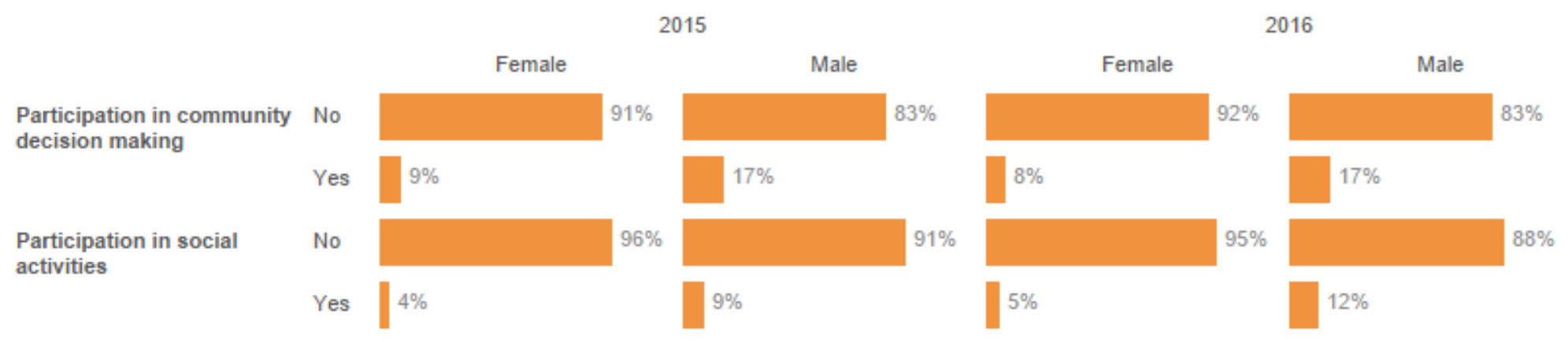

Source: Household interviews

At household level, focus group participants reported some changes in decision making as a direct consequence of the prolonged conflict experience, including increased participation of female household members in income-generating activities. This change was reported more often in urban areas, where women have better income opportunities than in rural areas. On decision making around household income use (see Figure 18), male and female respondents to the household survey reported differently. More than half (52\%) of female respondents reported that such decisions are made only by their husband or another male household member, while only $39 \%$ of male respondents reported that males are the only decision makers (male and female average: $46 \%$ ). $25 \%$ of female respondents reported that only the wife/another female household member decides how household income is spent, while only $2 \%$ of male respondents agreed with this (male and female average 14\%). No large differences between rural and urban settings were observed.

Focus group discussions revealed that decision making is often perceived differently from controlling the use of economic resources. In general, and while men continue to be perceived as the main decision makers at household level, the role of women in controlling the use of resources has increased since before the conflict. As one female focus group participant in Taiz said: 'Our husbands used to bring goods to the house. But we don't know if they can bring more tomorrow. So they leave it in the hands of us women to spend the money more wisely and for the benefit of the family.'

Female respondents to the household survey tended to report being less engaged in financial decision making, which is largely considered the responsibility of their spouse/another male household member. They reported being more engaged in decisions related to children's welfare and education. Male respondents reported a higher level of decision-making responsibility compared to female respondents. They agreed, however, that household mobility (including the decision to migrate or to visit relatives) is usually a joint decision with their spouses.

Among IDPs, type of residence is a key factor in who controls household income. A striking $83 \%$ of IDPs living in collective centres report that only the husband/male household member takes financial decisions (17\% wife and husband together), while IDPs living with relatives are more likely to take joint decisions as wife and husband (67\%). IDPs in collective centres are the poorest and often more conservative. Additionally, because of the lack of privacy in the camps, men take responsibility for protecting family assets. According to focus group participants, participation in decision making related to household expenditures has increased in IDP communities, especially where men have lost their access to income. For male household members within marginalized groups, their traditional role in household decision making 
remained high as a result of the predominant culture among these groups, despite the growing involvement of women in generating income.

Figure 18: Decision makers on how household money is spent by population group

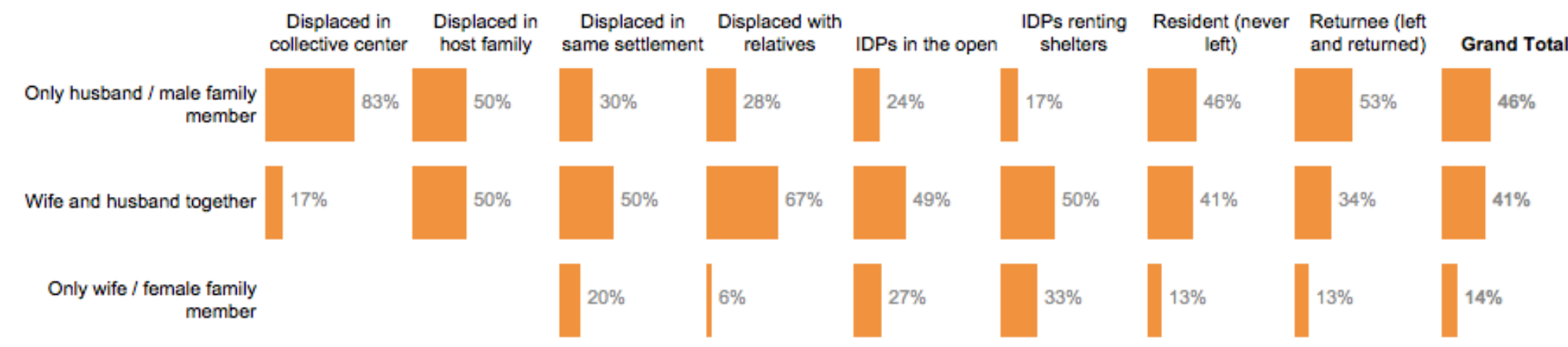

Source: Household interviews

\section{Case study: Hamida's story}

I am a government employee and a housewife. I used to spend my own salary on myself, because my husband, who was working in Sana'a, used to cover the family expenses. Then my husband lost his job due to the conflict. He returned home but couldn't find another job. Now I spend all my income on the family. I also joined a new organization that helps families in my village to increase their incomes. And I am now a volunteer with Social Fund for Development. All this gives me more power to influence decision making in my village.

Since my husband returned home he assists me with the housework. Now he is responsible for collecting water, he cooks when I am away, and he takes care of the children, while it is my responsibility to cover the family's expenses.

(Hamida, 31 years, Taiz)

\section{ACCESS TO SERVICES}

Even before the current crisis, there was insufficient access to healthcare and basic education in Yemen, especially in rural areas and the highlands. ${ }^{72}$ Key issues include restrictions on mobility for women and girls due to cultural norms, which are further aggravated by restrictions imposed by the conflict parties. Conflict and displacement bring instability and redefine gender roles in conflict-affected populations, leading to further breakdowns in community support systems and protection mechanisms, and availability of and access to basic services. Many Yemeni families have had to flee fighting, sometimes in the middle of the night, with little or no belongings.

According to the Humanitarian Response Plan 2016, Yemen's gender context creates additional obstacles to ensuring equity and accountability in assistance, and relief providers face difficulties in reaching women and girls even in communities where humanitarian access is unrestricted. The Access Monitoring and Reporting Framework has included an additional reporting element in Yemen that tracks restrictions limiting direct access to or engagement with conflict-affected women. ${ }^{73}$ 


\section{FREEDOM OF MOVEMENT}

The conflict has had a major negative impact on the freedom of movement of men and women due to the absence of security forces, proliferation of armed groups, widespread presence of weapons, large numbers of checkpoints on roads, widespread recruitment of children and young men, increased risk of arrest and detention, and imposition of curfews in most cities. Even before the crisis, women usually required accompaniment by a male relative (for movements outside the place of residence) or by another woman or child (within the place of residence). This restriction has increased as a result of the conflict, making it more difficult for women to access services. For men, the conflict has brought new restrictions on freedom of movement, particularly to other towns or governorates.

According to female respondents in the household survey, key factors limiting women's freedom of movement before the crisis included the lack of cultural acceptance $(51 \%)$ and the costs of transportation (24\%). This has changed: while cultural acceptance still ranks highest, 'lack of security' is now the second major obstacle to freedom of movement cited by women. For male respondents, the main obstacles are now the lack of security (55\%) and the costs of transportation (44\%).

Figure 192: Main obstacles to freedom of movement pre-crisis/today by sex

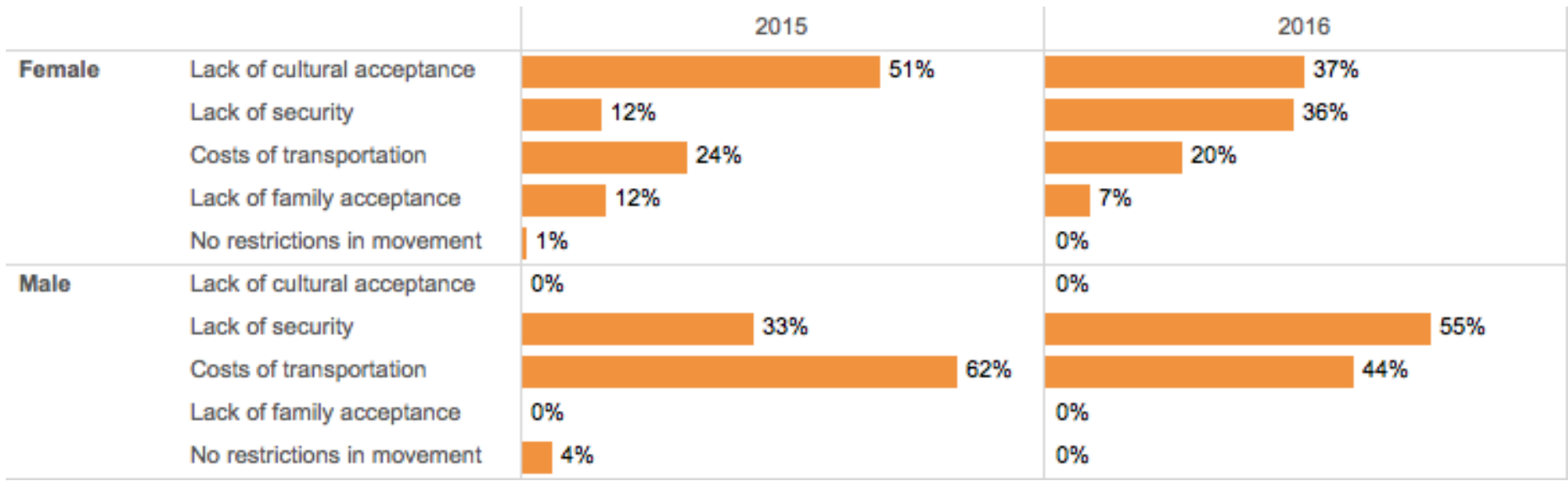

Source: Household interviews

According to male focus group participants, men are especially targeted at checkpoints and risk arrest or detention when travelling. In areas controlled by less conservative militias, women who are not from marginalized communities are generally more respected and are stopped less often than men. Participants in some areas report that this has led to a trend of households sending women rather than men to markets. However, women and girls, and especially members of marginalized communities, remain extremely vulnerable to harassment in many situations.

In areas controlled by radical Islamic groups such as AQAP, focus group participants reported that men at checkpoints increasingly insist on 'Mahram' - the cultural obligation of women to be accompanied by males in public. In Abyan, which has the highest number of women working in public services including hospitals and schools, this is particularly problematic. As one female participant in Abyan reported: 'Women cannot go easily to work any more because they don't always have a male companion available.' Even when using public transport, women in this area reported being afraid of being stopped at checkpoints and asked where their male escort is. 
Figure 20: Freedom of movement pre-crisis/today by sex

\begin{tabular}{l}
$2015 \quad$ To collect humanitarian assistance \\
To go to work / earn money \\
To the health centre \\
To the local market or shops \\
To the nearest town \\
To visit family in another location \\
To visit friends or family in the same neighbourhood \\
Travel to another governorate \\
To collect humanitarian assistance \\
To go to work / earn money \\
To the health centre \\
To the local market or shops \\
To the nearest town \\
To visit family in another location \\
To visit friends or family in the same neighbourhood \\
Travel to another governorate \\
\\
\hline
\end{tabular}

Value

Travel without any restriction

Only when accompanied by another woman or child

Only when accompanied by a male relative

No travel possible

Not applicable

Source: Household interviews

\section{ACCESS TO HUMANITARIAN ASSISTANCE}

Women's ability to access humanitarian aid differs depending on location. According to the UN, women and girls in Yemen often remain invisible to humanitarian actors and miss being targeted with aid assistance. ${ }^{74}$ In some places women can be reached directly, whilst in others aid is received through their male relatives. Challenges women face in accessing assistance, especially outside their communities, are even more acute for female-headed households, which comprise over $30 \%$ of displaced households in some areas. The Humanitarian Response Plan 2016 reported that in 2015, humanitarian organizations in Yemen improved the gender sensitivity of their projects; for example, several clusters are now reporting sex- and agedisaggregated data and using this data to inform their response. ${ }^{75}$ However, gaps remain in terms of implementation, monitoring and reporting. Alternatives, including women-only distributions and/or direct household delivery services, could be explored further. ${ }^{76}$

More than half of the interviewed households (56\%) reported receiving humanitarian assistance during the previous three months. The percentage is higher in urban areas $(65 \%)$ than in rural areas $(46 \%)$. Assistance is mainly collected by male adults ( $88 \%$ in urban and $74 \%$ in rural areas), and to a lesser extent by female adults (14\% rural and $9 \%$ urban). This confirms findings from previous assessments, indicating that restrictions on mobility are an obstacle for women and girls. ${ }^{77}$ Lack of official papers also makes it difficult for women, boys, and girls to register for 
food assistance. In rural areas, $7 \%$ of respondents reported that men and women collect aid together, while only $1 \%$ of respondents in urban areas reported that this is the case.

The majority of respondents $(72 \%)$ reported that there is 'no difference in the assistance provided to males and females', with no difference between urban and rural areas. Where a difference was reported, the main reasons given include that there is 'not assistance for all' $(71 \%)$, or that priority is given 'only to men' $(17 \%)$ or 'only to women' $(11 \%)$. Notably, male respondents reported a higher percentage of prioritized assistance for women (21\%) compared to female respondents $(9 \%)$.

$67 \%$ of respondents reported that relief agencies have assessed humanitarian needs on the ground. The percentage is similar in urban and rural areas, but is higher for male respondents $(75 \%)$ than female respondents $(60 \%)$. Talking directly to families is reported to be the main method of data collection ( $34 \%$ average male/female respondents), followed by talking only to women $(25 \%)$ or only to men $(22 \%)$.

\section{ACCESS TO REGISTRATION AND INFORMATION}

Women's illiteracy is an obstacle to accessing and understanding relevant information, consequently reducing women's access to assistance and other services. In particular, women, children, elderly and disabled people often faced difficulties in registering for official IDs, especially in rural areas. This presents a major obstacle when they are heads of households and all family members depend on their official ID to be entitled to humanitarian aid. In some areas, Yemeni women cannot travel alone to the registration point, and need to be accompanied by a male relative. Elderly and disabled people can also face more mobility difficulties. $^{78}$

\section{ACCESS TO HEALTHCARE}

Health services in Yemen are collapsing under the strain of the conflict. The UN estimates that 14.1 million people lack sufficient access to healthcare; 3 million children and pregnant or lactating women require malnutrition treatment or preventive services. Medical supplies for mass casualty management and medicine for chronic diseases are increasingly in short supply. Nearly 600 health facilities have stopped functioning due to conflict-related damage or lack of fuel, staff and supplies.
'My wife went to the hospital. They said there was no electricity to do medical tests. The hospital was full of casualties of war.'

- Male, Hajjah

Yemen's health system was already stretched before the conflict, with three doctors per 10,000 people in 2010. Restrictions on women's mobility, as well as the lack of female health workers and medical staff in remote rural areas, made it difficult for women to access basic health services for themselves and their children. ${ }^{79}$ Yemen already had a high maternal mortality rate estimated as 148 deaths per 100,000 live births. $55 \%$ of deliveries were not attended by skilled medical professionals, due in large part to a lack of female skilled birth attendants in rural areas. With disruption to normal health service provision and a further decrease in female health workers, this is likely to worsen. ${ }^{80}$

Resources are often unavailable to provide routine medical care, and families are increasingly unable to cover the costs of transportation to health facilities outside their districts. Focus group participants confirmed that women, especially pregnant women in rural areas, children under 
five and people suffering from chronic diseases, are particularly disadvantaged by the lack of gender-sensitive health services.

Men are particularly at risk of injury during fighting. They are often in need of specialist services to address disabilities or to provide rehabilitation or psychosocial support. ${ }^{81}$ People living in areas directly affected by conflict face additional risk of injury and further reduced availability of health services. IDPs living in remote areas or in areas where existing services are stretched often have no access to medical care. Both male and female participants reported resorting to buying medicine at pharmacies without medical consultation, increasing health risks, especially for women, children and individuals with chronic diseases in rural areas.

Access to health services varies between the assessed governorates, but has declined everywhere as a result of the crisis. While the majority of respondents in Abyan and Aden reported that health services are available 'always' or 'most of the time', respondents in Hajjah and Taiz reported markedly reduced access to health services. This is particularly a challenge for women: at the time of the assessment, access to maternal health and family planning services was a challenge for half of the female population in Hajjah, and for the majority (67\%) in Taiz.

\section{Figure 21: Access to maternal health and family planning services pre-crisis/today by urban/rural setting}

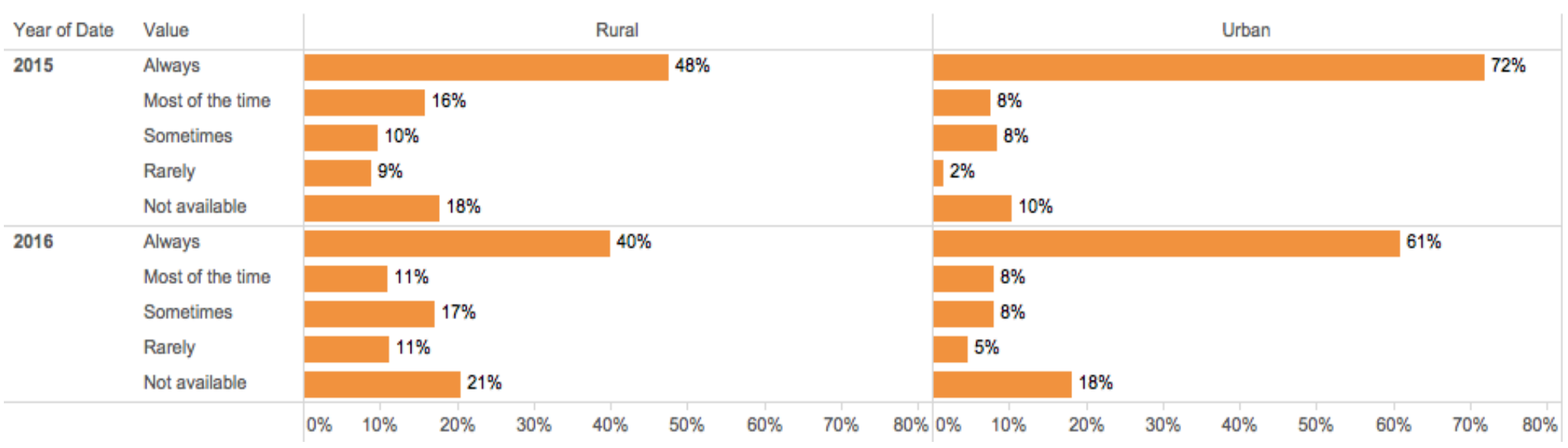

Source: Household interviews

Today, the United Nations Population Fund (UNFPA) estimates that 2.6 million women of reproductive age have been affected by the prolonged conflict, including 257,000 pregnant women. An estimated $15 \%$ of the pregnant women suffer maternal or obstetric complications which could become life-threatening without access to professional medical care. ${ }^{82}$ More than 522,000 women are currently estimated to be pregnant in Yemen - nearly 80,000 of whom are expected to face complications in delivery. ${ }^{83}$

According to respondents to the household survey, maternal health services are 'not available' or 'rarely' available for $32 \%$ of women in rural areas and for $23 \%$ in urban areas. The main reasons given are that maternal health services are not functional $(44 \%)$, the household cannot afford the health services $(31 \%)$, and it is unsafe to travel to available facilities $(9 \%)$. The challenges are more evident in rural areas. The absence of female health staff is a key constraint for $11 \%$ of female respondents in rural areas ( $3 \%$ urban). 
Figure 22: Reasons for lack of access to maternal health and family planning services today by urban/rural setting

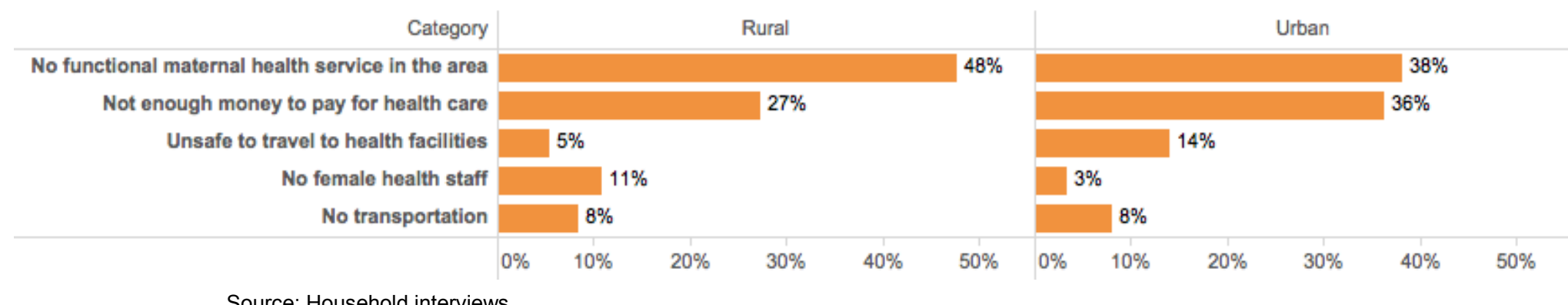

Some women reported increased pregnancy rates within their communities during the conflict because men are at home more often and for longer periods. Women also reported a lack of reproductive health services. Also, female focus group participants reported that women in their community try to get pregnant to benefit from food assistance that is only available to pregnant women. This could lead to preventable maternal and infant deaths, unwanted pregnancies and subsequently unsafe abortions.

\section{ACCESS TO FOOD AND LIVELIHOODS}

Amidst the conflict and economic crisis, half of conflict-affected people have lost their livelihoods. The reasons people have lost their livelihoods are diverse and particular, but the impact is broadly the same: it is now more difficult for them to meet their basic needs, a challenge which has been exacerbated by rising food, fuel and water prices. ${ }^{84}$ Cross-border trade with Saudi Arabia used to be a key source of income in the western part of Hajjah, including for a large number of marginalized communities (though small trade, daily labour and transport of goods across the border, especially of goats and qat). Farmers in conflict-affected areas missed the planting season as a result of displacement, destruction of assets, water and fuel shortages, and other missing agricultural inputs. ${ }^{85}$ Women in areas controlled by armed Islamist groups face increased difficulties getting to work. Women in rural areas reported increased barriers (landmines in Abyan, armed groups in Abyan, Hajjah and Taiz, and airstrikes in Hajjah) in accessing the natural resources that they had relied on in recent years.

As a result of the loss of traditional livelihoods, participants in the focus group discussions reported that men are now working in jobs that would have been 'unacceptable' before the crisis, including selling goods in the street, collecting firewood, construction work, mining, butchery, hairdressing and begging. There are some positive examples of coping strategies, or at least of less negative strategies. Some day labourers and traders are able to find a few days' work as a result of the movement of people. ${ }^{86}$ There are also some examples of women finding new sources of income by providing repair services for the increasingly common solar power systems.

Overall, however, families are increasingly resorting to negative coping mechanisms to meet their basic needs. These range from relying on help from relatives or neighbours, buying cheaper, less nutritious food, limiting portion sizes and reducing the number of meals, to borrowing food or money. According to a recent United Nations Development Programme (UNDP) survey, $42 \%$ of respondents had borrowed money in the past month. ${ }^{87}$

Worryingly, there is also an increase in child labour (both girls and boys) as households struggle to make ends meet. Participants in focus group discussions observed school-aged girls engaged in selling goods in all sample areas, especially in urban areas but also increasingly in rural settings. While only $1.46 \%$ of respondents in the UNDP survey reported resorting to sending their children to work, ${ }^{88} 14 \%$ of respondents in the household survey conducted for this 
research stated that boys 'need to work for money'. This rose to $25 \%$ in rural areas. Children face multiple protection concerns when they are working, including hazardous conditions and recruitment by armed groups; this is particularly the case for IDPs and other vulnerable individuals.

The ramifications of rising prices and loss of income are apparent in deteriorated food security, particularly in conflict-affected areas. The UN estimates that nearly 14.4 million Yemenis are food insecure, with 7.6 million severely food insecure. Nearly 320,000 children are severely acutely malnourished. ${ }^{89}$ The impact of the conflict on access to food was mentioned in all focus group discussions as one of the biggest challenges in all assessed governorates, particularly in areas with armed conflict, and especially for marginalized and displaced households. Pre-crisis assessments in Yemen demonstrated that women in food-insecure families often eat less in order to provide for their children - a phenomenon likely to increase amid rising food insecurity. ${ }^{90}$ Children under five and pregnant women are most at risk of malnutrition. Femaleheaded households experience higher levels of food insecurity than male-headed households. ${ }^{91}$

\section{ACCESS TO EDUCATION}

The education system in Yemen is weak, especially in rural areas. It is not compulsory for parents to send their children to school. Before the current surge in conflict, $43 \%$ of females and $21 \%$ of males had never attended school; $12 \%$ of females reached secondary school or higher, compared with $23 \%$ of males. Rural females and males were about twice as likely as their urban counterparts to have no education. ${ }^{92}$ Cultural norms, long distances to schools and a lack of female teachers (particularly in rural areas) as well as limited employment prospects reduced girls' access to education. The conflict has exacerbated this.

Comparison of 2013 with 1997 data shows that there had been some improvement in educational attainment prior to the current crisis. Between 1997 and 2013, the proportion of those aged six and over with no education declined from $67 \%$ to $43 \%$ for females, and from $33 \%$ to $21 \%$ for males. ${ }^{93}$ However, the conflict has reversed most of these gains. According to the UN, 1.8 million children or one-third the school-age population in Yemen have been out of school since the beginning of the conflict in March 2015. In 2015, the percentage of Yemeni women who are illiterate was projected to again reach $66 \%{ }^{94}$

More than 1,100 schools are currently unfit to reopen for the school year, the start of which has already been delayed several times due to conflict. In 2015, 174 schools were destroyed and 611 damaged since the conflict began. In addition, 260 schools are hosting IDPs, affecting access to education for 91,000 children. Armed groups have occupied 58 schools - almost all of them in Taiz. ${ }^{95}$ Displacement of children, teachers and other educational staff compounds the situation. The UN estimates that about 416,000 school-aged children are among the 2.3 million IDPs in the country, while the number of displaced teachers is unknown. ${ }^{96}$

Respondents of the household survey confirmed that access to education for both girls and boys has declined as a direct consequence of the prolonged conflict in all four assessed governorates. The percentage of boys and girls with access to regular education declined between March 2015 and today, from $69 \%$ to $60 \%$ on average, though the figure is higher in urban than rural areas. 
Figure 23: School-age children with access to education pre-crisis/today

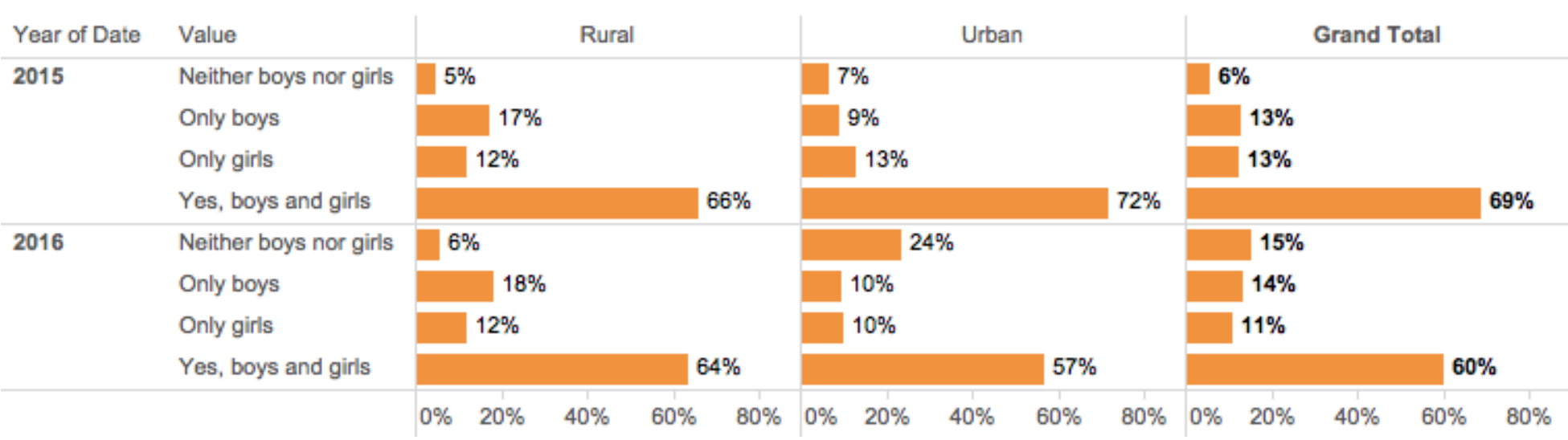

Source: Household interviews

In areas where children can go to school, participants in the focus group discussions reported a chronic lack of teachers and overcrowded classrooms, negatively affecting the quality of education. IDP children who lack their education certificates are often unable to join schools in the host communities. Participants also reported instances where children of marginalized groups are not allowed to join schools, in violation of Education Office directives. Participants confirmed the availability of some female teachers in urban areas, but only a very limited number in rural settings. This creates additional hurdles for girls.

The main reasons cited for why girls cannot go to school were that it is considered unsafe, especially in rural areas ( $67 \%$ of respondents), followed by the need for girls to work at home $(27 \%)$. The main reason given for why boys cannot go to school is that the household does 'not have enough money to send all children to school' ( $71 \%$ of female and $80 \%$ of male respondents). Instead of sending their boys to school, $14 \%$ of respondents reported that boys 'need to work for money'; the figure is highest in rural areas (25\%).

Access to adult education has also declined since the beginning of the crisis in 2015 , in all four assessed governorates. On average, $55 \%$ of respondents had no access to adult education in 2015. Today, this percentage has increased to $76 \%$. This is especially a problem for women. $83 \%$ of female respondents indicated that they have no access to adult education (men: $63 \%$ ), especially in rural areas. Other key challenges faced by women include the lack of government training and support for Women's Development offices and rural women extension agents. ${ }^{97}$

\section{ACCESS TO WATER AND SANITATION}

Yemen is one of the most water-scarce countries in the world. The UN estimates that 19.3 million people do not have access to safe drinking water and sanitation - twice as many as before the conflict - as a result of fuel shortages, damage to infrastructure and increased prices from private vendors. ${ }^{98}$ In areas with hot temperatures and areas of intensified armed clashes, water purchase accounts for a large proportion of family income, and frequently results in disputes between IDPs and host communities.

Pre-crisis, the majority (59\%) of people accessed water from an improved source of water, but nine out of ten households did not treat their water and only 5.5\% used an appropriate treatment method. According to the household survey, $52 \%$ of urban and $40 \%$ of rural households are currently connected to piped water. Families without piped water in rural areas rely on community wells located inside $(17 \%)$ or outside $(30 \%)$ the village. In urban areas, $25 \%$ of the households surveyed rely on water trucking to meet their needs. 


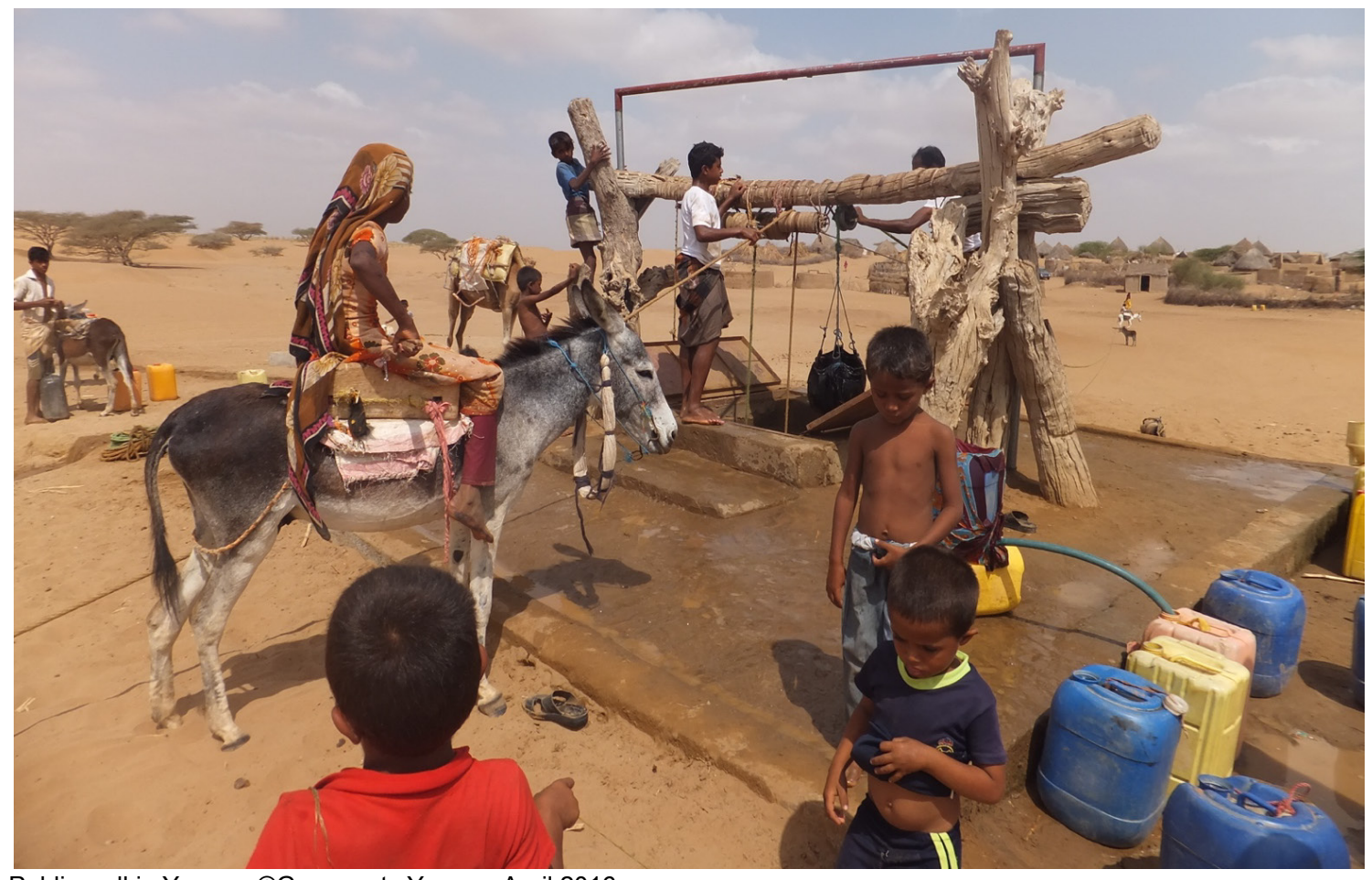

Public well in Yemen. @Grassroots Yemen, April 2016

The time needed to collect water has increased in all assessed areas since before the crisis. More than half of the respondents (55\%) to the household survey in both rural and urban areas reported that it currently takes them more than one hour to collect water, and this often needs to be done several times a day. The water points are generally described as safe. Only six respondents reported that water points are not always safe, and female respondents indicated that they are going in groups to these water points. For households without piped water, it is primarily the responsibility of women and girls to collect water, especially in rural areas (see Figure 24). This often means travelling long distances (30 minutes or more) to the detriment of their ability to attend school or engage in economic activity. ${ }^{99}$

Figure 243: Responsibility to collect water pre-crisis/today by urban/rural setting

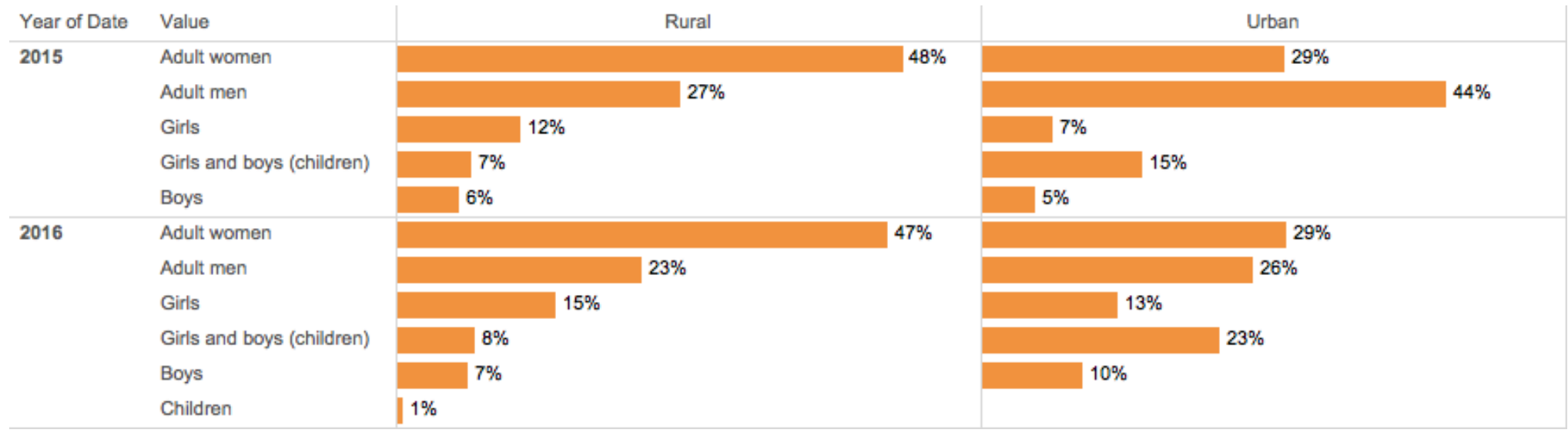

Source: Household interviews

More than half of households reported sharing improved toilets with others, while $25 \%$ of households have no toilet at all. There are large differences in sanitation methods between urban and rural areas. ${ }^{100}$ Latrine facilities were generally described by respondents as safe, but $16 \%$ of respondents in rural areas and $18 \%$ in urban areas describe facilities as unsafe. Female respondents were more likely to report latrine facilities as unsafe, especially in urban areas. Reasons given range from inappropriate design or materials (37\% of female respondents), no lock on the door $(31 \%)$ or no latrine at all $(21 \%)$. In urban areas with a higher population 
density, female respondents reported additional problems, including that the latrines were not secure at night, were located in unsafe areas, or lacked separate spaces for men and women (6\% each).

Women and girls are especially vulnerable when they have to travel long distances to use shared toilets, or practise open defecation. Many choose to wait until nightfall (sometimes more than 12 hours), making them vulnerable to harassment or violence. Many also limit their consumption of food and drink to delay the need to relieve themselves. Both strategies increase the likelihood of urinary tract infections. The shame and indignity of defecating in the open, and the lack of water for washing clothes and for personal hygiene, also affect women's selfesteem. ${ }^{101}$

Uncollected waste, especially in urban areas, is exacerbating the risks of a public health crisis. ${ }^{102}$ Sewage treatment is at risk throughout Yemen and is only partially operational in Sana'a and Sa'ada. ${ }^{103}$ According to key informant interviews, children often suffer from diarrhoeal and other waterborne diseases. Women play a critical role in promoting good hygiene practices at household level, such as hand washing and proper waste disposal. They are also responsible for preparing food and managing water collection, storage and treatment.

\section{ACCESS TO ELECTRICITY AND FUEL}

Interviewed households reported that access to electricity has declined on average from $84 \%$ before the crisis to $61 \%$ today (no large differences reported between female and male respondents, or urban and rural areas). $74 \%$ of households reported that electricity is available from between 5 and 12 hours a day, while $7 \%$ reported having electricity for less than four hours a day. Respondents in Hajjah reported less access to electricity compared to the other governorates ( $12 \%$ reported less than four hours a day).

Figure 25: Access to electricity pre-crisis/today by governorate

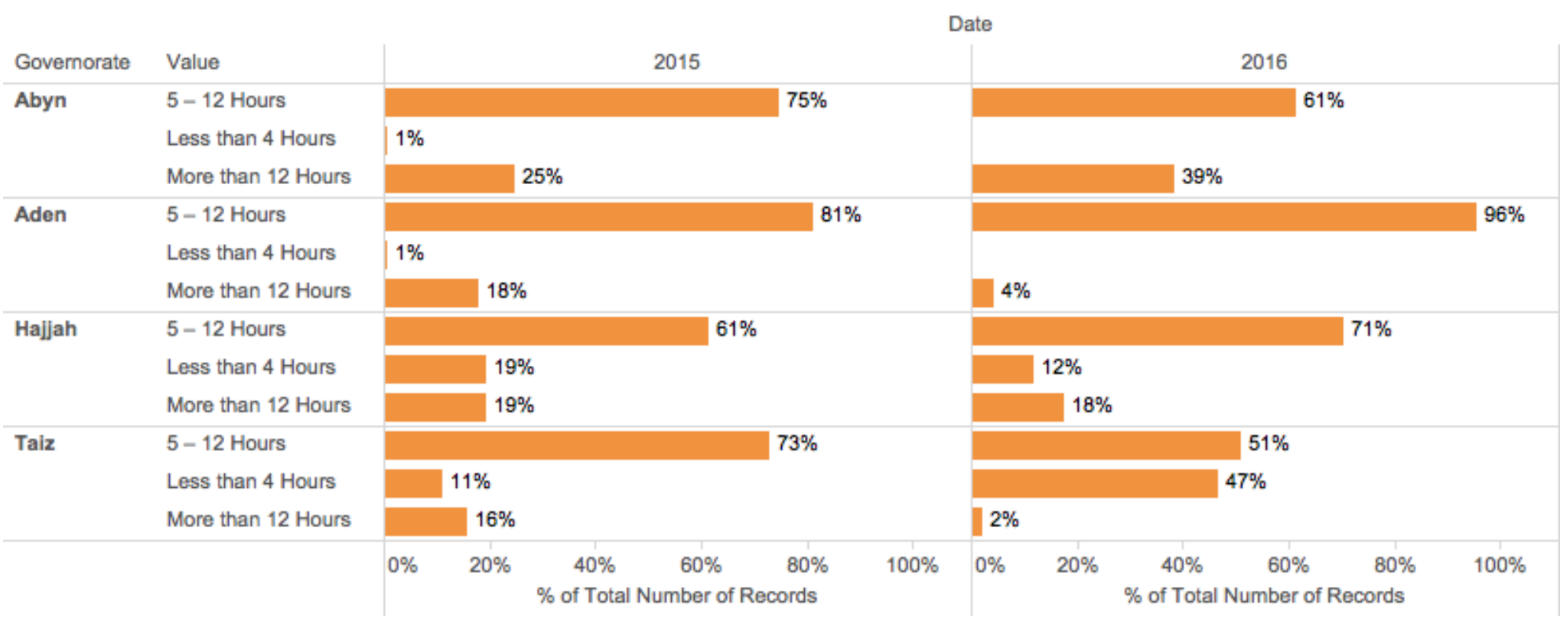

Source: Household interviews

Female focus group participants reported that many women and children in the coastal areas where temperatures are high are suffering as a result of power cuts, and are not able to refrigerate food and medicines for longer periods, with resulting negative health consequences. Participants in the focus groups also pointed out that the fragile security situation is exacerbated by the lack of lighting, increasing the risk of GBV. This particularly affects women and girls 
practising open defecation mainly at night time. Electricity shortages have also had a negative impact on children's ability to study. The lack of reliable access to electricity has also led to the collapse of some businesses, for example those reliant on refrigeration.

Cooking fuel shortages (and the resulting spike in prices) is considered a major problem by female focus group participants, with many households now allocating large parts of their income to the provision of gas. According to the household survey, since the beginning of the crisis the number of households with access to gas, the preferred cooking fuel, declined from $80 \%$ to $46 \%$ today. Access is worst in Hajjah, where half of all respondents reported having access to gas in 2015 . Today only $4 \%$ can access gas, which has essentially been replaced as cooking and heating fuel by firewood, especially in rural areas.

According to male focus group participants, competition for scarce resources, including gas or even firewood, has resulted in conflicts between IDPs and host communities. Female participants from rural communities in Hajjah expressed fears about how they will cope in future if trees continue to be cut down at the current rate.

Pregnant and lactating women together with their children have been most affected by the lack of fuel, and are the most vulnerable to the risk of fire; this is particularly the case within marginalized groups and for IDPs in makeshift shelters (tents and huts). Finally, extremely vulnerable households often resort to burning plastic materials for cooking purposes, which causes substantial health threats.

The responsibility for collecting fuel has changed since the beginning of the crisis, along with the change to the type of fuel used. It was mainly the duty of adult men to collect fuel (primarily gas) before the crisis; now it is increasingly the responsibility of women to collect firewood, especially in rural areas and among IDPs in host communities. This increases their risk of exposure to GBV. Forms of GBV reportedly include mainly verbal harassment, especially of marginalized women. Furthermore, as with water collection, the time women and girls spend collecting firewood takes away from time and effort that could otherwise have been spent on economically productive activities.

Figure 26: Responsibility to collect fuel pre-crisis/today by urban/rural setting

\begin{tabular}{|c|c|c|c|c|c|c|c|}
\hline \multirow[b]{2}{*}{ Sub-district is } & \multirow[b]{2}{*}{ Value } & \multicolumn{6}{|c|}{ Date } \\
\hline & & & 2015 & & \multicolumn{3}{|c|}{2016} \\
\hline \multirow[t]{4}{*}{ Rural } & Adult men & \multicolumn{3}{|c|}{$71 \%$} & & $47 \%$ & \\
\hline & Adult women & \multicolumn{2}{|c|}{$25 \%$} & & & \multicolumn{2}{|c|}{$48 \%$} \\
\hline & Boys & $2 \%$ & & & | $1 \%$ & & \\
\hline & Girls & $2 \%$ & & & $4 \%$ & & \\
\hline \multirow[t]{6}{*}{ Urban } & Adult men & & & $88 \%$ & & \multicolumn{2}{|c|}{$65 \%$} \\
\hline & Adult women & 8 & & & \multicolumn{2}{|c|}{$23 \%$} & \\
\hline & Boys & | $3 \%$ & & & \multicolumn{2}{|c|}{$8 \%$} & \\
\hline & Girls & $1 \%$ & & & \multicolumn{2}{|l|}{$4 \%$} & \\
\hline & & $0 \%$ & $50 \%$ & $100 \%$ & $0 \%$ & $50 \%$ & $100 \%$ \\
\hline & & \multicolumn{3}{|c|}{$\%$ of Total Number of Records } & \multicolumn{3}{|c|}{$\%$ of Total Number of Records } \\
\hline
\end{tabular}

Source: Household interviews

The importance of improved access to energy sources was highlighted in many focus group discussions during this assessment, but also as a possible entry point for empowering communities, and especially women, across all sectors. This includes improved protection, reduced risk of miscarriages (for pregnant women carrying heavy loads of wood and water), improved education, improved access to food (instead of spending money on gas bottles) and 
so on. Possible interventions could include support to small-scale electrification projects ('offgrid systems') at community or household levels.

\section{ACCESS TO JUSTICE}

Even before the current conflict, women in Yemen faced difficulties in accessing the courts because of social constraints, widespread discrimination, as well as cultural norms and certain procedural and administrative obstacles inside the system. Female focus group participants reported that seeking legal assistance is often considered a violation of cultural norms and might lead to greater harassment or violence. At the same time, because of high illiteracy rates and a lack of public awareness, women remain unaware of their constitutional rights, further inhibiting their ability to access the justice system.

When women are involved in court cases, they can find themselves abandoned by their families with no place to turn and no support to fight the accusations. These women, even if they can afford the costs of legal prosecution, will still have to go through a discriminatory system with limited awareness of their legal rights, believing that male members of the community should not be challenged. Some women experience discriminatory treatment from enforcement institutions, which violates their rights.

When asked about the accessibility of legal support and police services, important differences emerged between male and female household respondents. For $97 \%$ of female respondents in rural areas, legal services are 'rarely' or 'never accessible' (male: 68\%). Access for women to legal services in urban areas is better than in rural areas, at about $10 \%$. Female participants in focus group discussions reported limited knowledge of how to access legal assistance, especially regarding property and inheritance disputes within extended families.

Figure 27: Access to legal support and police services by sex

\begin{tabular}{|c|c|c|c|c|c|}
\hline \multirow[b]{2}{*}{ Sub-district is } & \multirow[b]{2}{*}{ Accessibility } & \multicolumn{2}{|c|}{ Female } & \multicolumn{2}{|c|}{ Male } \\
\hline & & Legal support & Police & Legal support & Police \\
\hline \multirow[t]{5}{*}{ Rural } & Always accessible & & & $12 \%$ & $13 \%$ \\
\hline & Often accessible & & & $8 \%$ & $8 \%$ \\
\hline & Sometimes accessible & $3 \%$ & $6 \%$ & $12 \%$ & $8 \%$ \\
\hline & Rarely accessible & $15 \%$ & $19 \%$ & $7 \%$ & $10 \%$ \\
\hline & Never accessible & $82 \%$ & $75 \%$ & $61 \%$ & $61 \%$ \\
\hline \multirow[t]{5}{*}{ Urban } & Always accessible & & $2 \%$ & $14 \%$ & $25 \%$ \\
\hline & Often accessible & $3 \%$ & $3 \%$ & $7 \%$ & $5 \%$ \\
\hline & Sometimes accessible & $10 \%$ & $12 \%$ & $5 \%$ & $9 \%$ \\
\hline & Rarely accessible & $19 \%$ & $24 \%$ & $4 \%$ & $7 \%$ \\
\hline & Never accessible & $68 \%$ & $59 \%$ & $70 \%$ & $54 \%$ \\
\hline
\end{tabular}

Source: Household interviews

Participants in the focus group discussions reported that that in most locations, courts have been closed since the start of the conflict in March 2015. In some locations, armed groups were reported as having created parallel legal systems and police forces. Participants reported a trend that people are increasingly approaching these institutions to seek justice due to the absence of formal mechanisms, to save time and resources, and to see the immediate implementation of verdicts reached (often in favour of the person who approached the armed groups first). 
Women's limited access to justice should be understood within the context of wider legal discrimination against women in Yemen. Women cannot marry without the permission of their male guardian; they do not have equal rights to divorce, inheritance or child custody; and a lack of legal protection leaves them exposed to domestic and sexual violence. Child and forced marriage are common. The National Dialogue Conference produced many recommendations to bolster women's and girls' rights. In response, in April 2014, the Minister of Social Affairs and Labour, and the Minister of Legal Affairs, submitted a draft Child Rights Law to the cabinet. The draft law sets the minimum age for marriage at 18 , and provides criminal penalties for its violation. The draft law also addresses other important rights for girls and women, including criminalizing the practice of female genital mutilation. The law remained pending in the cabinet at the time of writing. ${ }^{104}$

\section{ACCESS TO COMMUNICATION}

Of all services previously run by government, telecommunications in Yemen has been less affected by the outbreak of conflict than other services. Landline, mobile networks and internet services remained largely at pre-conflict levels in most parts of the assessed areas.

Nevertheless, access to telephone and internet services was described by household respondents as generally low. It is better for men than for women, and higher in urban than rural areas. $95 \%$ of female respondents in rural areas and $89 \%$ in urban areas reported that internet is 'rarely' or 'never accessible' (male: $98 \%$ rural and $83 \%$ urban).

Figure 28: Access to telecommunications services by sex

\begin{tabular}{|c|c|c|c|c|c|}
\hline \multirow[b]{2}{*}{ Sub-district is } & \multirow[b]{2}{*}{ Accessibility } & \multicolumn{2}{|c|}{ Female } & \multicolumn{2}{|c|}{ Male } \\
\hline & & Internet & Telephone & Internet & Telephone \\
\hline \multirow[t]{5}{*}{ Rural } & Always accessible & $2 \%$ & $31 \%$ & $7 \%$ & $73 \%$ \\
\hline & Often accessible & & $6 \%$ & $2 \%$ & $5 \%$ \\
\hline & Sometimes accessible & $3 \%$ & $15 \%$ & $2 \%$ & $7 \%$ \\
\hline & Rarely accessible & $10 \%$ & $19 \%$ & $9 \%$ & \\
\hline & Never accessible & $85 \%$ & $30 \%$ & $79 \%$ & $16 \%$ \\
\hline \multirow[t]{5}{*}{ Urban } & Always accessible & $7 \%$ & $49 \%$ & $9 \%$ & $83 \%$ \\
\hline & Often accessible & $1 \%$ & $4 \%$ & $2 \%$ & $6 \%$ \\
\hline & Sometimes accessible & $4 \%$ & $15 \%$ & $6 \%$ & $1 \%$ \\
\hline & Rarely accessible & $4 \%$ & $4 \%$ & $3 \%$ & \\
\hline & Never accessible & $85 \%$ & $27 \%$ & $80 \%$ & $10 \%$ \\
\hline
\end{tabular}

Source: Household interviews

Limited use of internet and telephone is largely an access rather than an availability issue. Reasons indicated by participants in the focus group discussions include cultural barriers, especially in more conservative rural areas, where the internet is still considered as 'western' or 'haram', especially for women. At the same time, women also reportedly lack the financial resources to buy the required hardware, or don't have experience using smartphones. $30 \%$ of rural and $27 \%$ of urban women reported never having access to a telephone; half ( $49 \%$ ) of rural women have phone access rarely or never. 


\section{THE WAY FORWARD}

This section draws on focus group discussions and key informant interviews conducted as part of this assessment. At the end of each meeting, participants were asked to share their strategic needs and aspirations. Additionally, during the validation workshop, participants representatives from national and international NGOs, UN agencies and government - were asked to reflect on how to operationalize the findings of the analysis. The objective was to identify entry points for programming and ways to utilize and modify available social capital for more gender-responsive initiatives. The responses from participants in the assessment and validation workshop form the basis of the list below. These are not recommendations in the traditional sense; rather they provide an on-the-ground perspective of the priorities, needs and aspirations of conflict-affected communities.

Overall, stability- and safety-dominated needs and aspirations were emphasized in most sites visited, especially among women in areas with active armed conflict; this is followed by reduced prices for essential commodities and fuel, access to basic services and opportunities to improve livelihoods. In areas with a high presence of displaced populations, participants prioritized the return to their areas of origin, and improved access to equitable and sufficient humanitarian assistance. Among the key informants, interviewed activists emphasized the need for changes in governance at community and national levels, improved access to information, peacebuilding initiatives at various levels and across all governorates, and greater freedom of movement. The needs and aspirations were categorized into the four main domains of this assessment: gender roles and relations; capacities and vulnerabilities; participation in decision making; and access to services and assistance.

\section{GENDER ROLES AND RELATIONS}

- Existing positive changes in gender roles and relations at household and community levels should be supported, especially the different positive coping strategies used by men, women, boys, and girls.

- Areas to explore could include coping strategies to address food insecurity, psychological distress, health issues, limited financial resources, mobility constraints, limited natural resources, social stigma, participation at community level, access to services, access to humanitarian aid, legal assistance, limited fuel and lighting, and access to counselling and information.

\section{CAPACITIES AND VULNERABILITIES}

- Gender-responsive initiatives to support the resilience of men and women in Yemen should build on existing capacities at community and household levels, including local conflictmitigation schemes.

- Community-based and community-level preparedness structures should be supported to build communities' resilience to shocks and conflict, through participatory planning, mitigation, and assessment of available resources (including alternative shelter, water resources, financial resources, or community contingency plans) with an explicit inclusive approach to ensure the participation of female IDPs, marginalized groups and wage labourers.

- The outreach capacity of community-level networks and stakeholders need to be strengthened, especially women's groups, community development groups and women's saving groups. 
- Women's cooperative saving groups should be supported and scaled-up. They have proven to be an effective community-based mechanism to support vulnerable families, not only in Yemen, and not only for saving schemes. Such groups could also provide a platform for income-generation activities and community-based health, accident and life insurance schemes. Building on indigenous, culturally accepted and tested schemes, supported by professional guidance and adopting best practices from similar contexts, could have a substantial impact for many conflict-affected communities.

- Formal and informal social protection mechanisms should be identified and strengthened to assist in addressing the high levels of insecurity and lack of safety in conflict-affected communities, especially for women.

- Existing GBV prevention and response structures need to be scaled up, including psychosocial support, legal assistance and safe shelter for GBV survivors, as well as training for health and community-based service providers to listen and provide emotional support.

\section{PARTICIPATION IN DECISION MAKING}

- Notwithstanding the need to increase engagement with women-led local NGOs, new genderresponsive strategies should include (more) males in community mobilization efforts, in recognition of their significant control over household resources and practices.

- Newly established committees should have, whenever possible, a membership of $50 \%$ women and $50 \%$ men, and equal numbers of women and men in leadership positions.

- At household level, gender-sensitive response initiatives can build on the growing role of women in income generation and their resulting increasing role in household decision making. Building on that, family-based income-generation projects can be further developed, preferably run by local community organizations which have been supported through training and capacity building.

- Efforts to improve coordination mechanisms, information sharing and adherence to international humanitarian norms should be scaled up among all stakeholders at the community level (including government, civil society organizations and INGOs).

- Sheikhs/Akhils, alongside local councils and community-based organizations, are essential contributors in efforts towards community acceptance and dialogue. For programmes specifically targeting women, sheikhs' wives and teachers should be engaged to improve outreach and community acceptance.

- Efforts to increase women's participation in community decision making should be rooted in strong, inclusive and participatory local gender and power analyses. Every community has different dynamics; for example, in some communities, local councils have high acceptance and play an active role, while in others the tribal leaders have more say, etc.

- Gender equality education through the formal education system, in coordination with the Ministry of Education, is another possible entry point for programming, for example, through awareness raising for schoolchildren.

- Organizations should ensure that their media messages are culturally sensitive, particularly in the way they present vulnerable women.

- Further research is required on the role of traditional women leaders within extended families or the community, and how they can be supported. Female focus group participants highlighted the role of such women, especially in rural areas, in providing consultation and representing women in a culturally appropriate manner in front of men in the family or community leaders. 


\section{ACCESS TO SERVICES AND ASSISTANCE}

\section{Livelihood opportunities}

- While promoting women's access to livelihoods is critical, organizations should also ensure that men and youth have adequate access to livelihoods activities. There are opportunities to work with men to diversify their skills and livelihoods activities as a way of building resilience.

- Programmes aimed at improving women's access to livelihoods should address the wide range of mobility issues women face, particularly in rural areas and areas controlled by armed groups.

- The reactivation and improvement of Social Welfare Fund programmes should be advocated, including a review of beneficiary lists and benefits. In light of current deficiencies in the lists, international organizations should use participatory approaches to identify and target the poorest households.

- Small-scale producers should be supported to improve marketing of their produce to be better able to compete with imported goods in agricultural markets.

\section{Basic services}

- Efforts to improve access to medical services should focus on increasing the number of female medical staff, the availability of maternal and child healthcare, and the affordability of healthcare.

- There needs to be development and improved availability of vocational training and education that would enable both literate and illiterate youth to gain access to immediate livelihood opportunities. Work to ensure that any trainings offered reflect the current aspirations and preferred learning styles of youth.

- Interventions for small-scale electrification projects ('off the grid' systems) should be piloted at community and household levels to provide households with alternative energy sources, including exploring ways to support existing women-led initiatives using solar power.

- The availability of mobile phone networks and internet connectivity could be a favourable entry point for targeted interventions to empower women, including the promotion of social media as a tool to introduce better coping mechanisms, early warning, availability of aid and more.

\section{Humanitarian aid}

- Male and female participants in focus group discussions requested more initiatives to support income-generating opportunities, especially for IDP women and host communities, including: a) inputs to support home-based work and training, b) special provision to help women with their care-giving responsibilities, c) support to vulnerable people who are not able to participate in such activities, and d) activities to prevent the recruitment of minors by armed groups.

- The interviewed male and female populations also emphasized the importance of being always consulted by relief providers in the design and implementation of humanitarian interventions, in order for their views to be taken into account. Concerns included the whole range of access to information about available aid, registration, targeting, distribution, and the availability of complaint mechanisms.

- When providing non-food item support, agencies should respect 'do no harm' principles. The provision of gas stoves might support some families, while it imposes economic pressure on others who are forced to buy expensive gas bottles instead of using their limited resources 
for other purposes. Wood stoves also increase the risk of fire, especially for IDP families living in improvised shelters and tents.

- The specific needs of polygamous households should be addressed when it comes to providing food, non-food items, hygiene kit distribution and shelter assistance, ensuring all the wives and their children have the same access to humanitarian resources.

- When making cash transfers conditional on girls' access to education, agencies should ensure that the 'do no harm' principle is respected. While it is good to create an increase in the number of girls going to school, households are sometimes putting their girls at risk while significantly increasing pressure on mothers, in order to qualify for cash transfers. 


\section{BIBLIOGRAPHY}

Bin Daair (2014), Samira. Gender issues in the new Yemen. Yemen Times, April 2014, accessed Mar 2016, http://www.yementimes.com/en/1774/opinion/3760/Gender-issues-in-the-newYemen.htm

CARE (2015a), CARE International, Rapid Gender Analysis of Yemen, June 2015

CARE (2015b), CARE International, GenCap, Different Needs, Hidden Needs? A scoping study of the inclusion of gender into assessments of the impact of 2015 conflict in Yemen, November 2015

CEDAW (2007), UN Committee on the Elimination of Discrimination Against Women, Convention on the Elimination of All Forms of Discrimination against Women Yemen, 13 March 2007

Colburn (2002), Marta, A Situation Analysis of Gender and Development in Yemen, 2002, Oxfam GB Yemen

ECHO (2016), Gender: Different needs, adapt assistance. ECHO Factsheet, 2016

HCT (2016) Humanitarian Country Team, Humanitarian Response Plan Jan-Dec 2016

HRW (2016), Human Rights Watch, Country Summary Yemen, January 2016

IASC (2014), GenCap, IDP registration - Gender, age and diversity considerations. Report of three discussion sessions, 2014

IASC (2015), Humanitarian Crisis in Yemen. Gender Alert. July 2015

ICAN (2016), International Civil Society Action Network. We will survive: Women's Rights and Civil Activism in Yemen's Endless War. Brief 14, Winter 2016

ICG (2016), $\quad$ Yemen: Is Peace Possible? International Crisis Group Middle East Report N¹67, 9 February 2016

IPTI (2016), Inclusive Peace \& Transition Initiative, Making Women Count - Not Just Counting Women, Graduate Institute Geneva, 29 Mar 2016

Jadallah (2015), Alma Abdul Hadi, PhD., Conflict Analysis of the Republic of Yemen for United National Country Team, June 2015

Jarhum (2016), Rasha: Status of Women during Conflict in Yemen. Reflections on WPS UNSC 1325 \& CEDAW $30^{\text {th }}$ Recommendation. Report for 'To Be For Rights and Freedoms', Aspen Institute 2016 (no date)

Koesfeld (2016), Michael van, British Red Cross, On the Precipice of Disaster, The Huffington Post, 13 Jan 2016

Logue (2014), Teresa, Yemen: Health Inequality Between the Genders, Yale Global Health Review, May 2014

LSE (2013), $\quad$ London School of Economics, Shakit, Wameedh, Women's political participation in Yemen, Dreaming of a state, Yemen Country Report, London, Oct 2013

MoH (2015), Yemen Demographic and Health Survey, July 2015, accessed Jan 2016, http://dhsprogram.com/pubs/pdf/FR296/FR296.pdf

MoPHP (2015), Ministry of Public Health and Population and Central Statistical Organization, National Health and Demographic Survey 2013, Sana'a, Yemen, July 2015

Mwatana (2015), Mwatana Organization for Human Rights: Blind Air Strikes - Executive Summary, 15 Dec 2015, accessed Mar 2016, http://www.mwatana.org/en/15122015445

NRC (2016), Norwegian Refugee Council, Yemen: On the Brink of Catastrophe. March 2016

OCHA (2014), UN Office for the Coordination of Humanitarian Affairs (OCHA). Yemen Humanitarian Needs Overview 2014. OCHA, 2014

OCHA (2015a), UN Office for the Coordination of Humanitarian Affairs (OCHA). 2015 Yemen Humanitarian Needs Overview, June Revision. OCHA, 2015

OCHA (2015b), Draft Humanitarian Needs Overview for 2016, October 2015 
OXFAM (2014), Informal Actors, Community, and the State, December 2014

OXFAM (2016a), Terms of Reference - Protection Assessment, January 2016

OXFAM (2016b), Making women count. The unequal economics of women's work. OXFAM Canada, March 2016

UNDO (2016), United Nations Development Programme, Yemen: Yemen Resilience Monitor: Communities coping with Conflict, April 2016

UNDP (2015a), United Nations Development Programme, Yemen: MDG Overview, accessed June 2015, http://www.ye.undp.org/content/yemen/en/home/mdgoverview/overview/mdg2. html

UNDP (2015b) Yemeni Polling Centre, UNDP Survey Findings Report, unpublished from October 2015

UNDP (2015c), United Nations Development Programme, Human Development Index: Table, accessed Jan 2016, http://hdr.undp.org/en/content/human-developmentindex-hdi-table. 2015

UNFPA (2009), Country Assessment on Violence against Women, UNFPA, no data and place

UNFPA (2015), As Yemen conflict drags on, women's vulnerability grows, 2 Nov 2015, accessed Jan 2016, http://www.unfpa.org/news/yemen-conflict-dragswomen $\% \mathrm{E} 2 \% 80 \% 99$ s-vulnerability-grows

UNICEF (2006), Multi Indicator Cluster Survey, 2006, accessed Jan 2016, http://www.childinfo.org/files/MICS3YemenFinalReport2006Eng.pdf

USAID (2014), Yemen Gender Assessment, January 2014, accessed Jan 2016, http://pdf.usaid.gov/pdfdocs/pa00jnrk.pdf

WEF (2014), World Economic Forum, The Global Gender Gap Report 2014, Geneva 2014

YPC (2015a), Yemen Protection Cluster, Task Force on Population Movements, 3rd Report, 6 July 2015

YPC (2015b), Yemen Protection Cluster, Task Force on Population Migration, 5th Report, 14 October 2015

Zyck (2013), Steven, Conflict Assessment of the Republic of Yemen. United Nations, 2013 


\section{NOTES}

1 Care (2015a) Rapid Gender Analysis of Yemen, June 2015.

2 CSO (2013) Statistical Yearbook

3 Ministry of Public Health and Population and Central Statistical Organization (2015) National Health and Demographic Survey 2013, Sana'a, Yemen, July 2015

4 Alma Abdul Hadi Jadallah (2015) Conflict Analysis of the Republic of Yemen for United National Country Team, June 2015

5 UN Office for the Coordination of Humanitarian Affairs (OCHA) (2015a) Yemen Humanitarian Needs Overview, June Revision. OCHA, 2015

6OCHA (2015b) Draft Humanitarian Needs Overview for 2016, OCHA: 2015.

7OCHA (2015b) Draft Humanitarian Needs Overview for 2016, OCHA: 2015.

8 OCHA (2015b) Draft Humanitarian Needs Overview for 2016, OCHA: 2015

9 OCHA (2015b) Draft Humanitarian Needs Overview for 2016, OCHA: 2015.

10 CARE (2015a) Rapid Gender Analysis of Yemen, June 2015.

11 Ministry of Public Health and Population and Central Statistical Organization (2015) National Health and Demographic Survey 2013, Sana'a, Yemen, July 2015

12 Ministry of Public Health and Population and Central Statistical Organization (2015) National Health and Demographic Survey 2013, Sana'a, Yemen, July 2015

13 Oxfam (2016a) Terms of Reference - Protection Assessmen, January 2016

14OCHA (2015b) Draft Humanitarian Needs Overview for 2016, OCHA: 2015.

15 Alma Abdul Hadi Jadallah (2015) Conflict Analysis of the Republic of Yemen for United National Country Team, June 2015

16 UNFPA (2015) As Yemen conflict drags on, women's vulnerability grows, 2 Nov 2015, accessed Jan 2016, http://www.unfpa.org/news/yemen-conflict-drags-women\%E2\%80\%99s-vulnerability-grows

17 OCHA (2015b) Draft Humanitarian Needs Overview for 2016, OCHA: 2015.

18 OCHA (2015b) Draft Humanitarian Needs Overview for 2016, OCHA: 2015.

19 OCHA (2015b) Draft Humanitarian Needs Overview for 2016, OCHA: 2015.

20 OCHA (2015b) Draft Humanitarian Needs Overview for 2016, OCHA: 2015

21 OCHA (2015b) Draft Humanitarian Needs Overview for 2016, OCHA: 2015

22 OCHA (2015b) Draft Humanitarian Needs Overview for 2016, OCHA: 2015.

23 OCHA (2015b) Draft Humanitarian Needs Overview for 2016, OCHA: 2015

24 Alma Abdul Hadi Jadallah (2015) Conflict Analysis of the Republic of Yemen for United National Country Team, June 2015

25 OCHA (2015b) Draft Humanitarian Needs Overview for 2016, OCHA: 2015.

26 CARE (2015a) Rapid Gender Analysis of Yemen, June 2015.

27 Alma Abdul Hadi Jadallah (2015) Conflict Analysis of the Republic of Yemen for United National Country Team, June 2015

28 CARE and GenCap (2015b) Different Needs, Hidden Needs? A scoping study of the inclusion of gender into assessments of the impact of 2015 conflict in Yemen, November 2015

29 OCHA (2015b) Draft Humanitarian Needs Overview for 2016, OCHA: 2015.

30 CARE (2015a) Rapid Gender Analysis of Yemen, June 2015.

31 CEDAW (2007) Yemen Country Report, 13 March 2007

32 CARE (2015a) Rapid Gender Analysis of Yemen, June 2015.

33 Alma Abdul Hadi Jadallah (2015) Conflict Analysis of the Republic of Yemen for United National Country Team, June 2015 
34 OCHA (2014) Yemen Humanitarian Needs Overview 2014. OCHA, 2014.

35 OCHA (2015b) Draft Humanitarian Needs Overview for 2016, OCHA: 2015.

36 IASC (2015) Humanitarian Crisis in Yemen: Gender Alert July 2015

37 Alma Abdul Hadi Jadallah (2015) Conflict Analysis of the Republic of Yemen for United National Country Team, June 2015

38 Alma Abdul Hadi Jadalla, (2015) Conflict Analysis of the Republic of Yemen for United National Country Team, June 2015

39 Pan Arab Project for Child Development ( 2003) Yemen Demographic and Maternal Health Survey

40 IASC (2015) Humanitarian Crisis in Yemen: Gender Alert July 2015.

41 Ministry of Public Health and Population and Central Statistical Organization (2015) National Health and Demographic Survey 2013, Sana'a, Yemen, July 2015

42 Ministry of Public Health and Population and Central Statistical Organization (2015) National Health and Demographic Survey 2013, Sana'a, Yemen, July 2015

43 Ministry of Public Health and Population and Central Statistical Organization (2015) National Health and Demographic Survey 2013, Sana'a, Yemen, July 2015

44 CARE (2015a) Rapid Gender Analysis of Yemen, June 2015.

45 This result could also reflect a sampling issue: Enumerators reported that the selection of male respondents was often difficult during daytime in the sampled villages. Those who were identified and interviewed were often government employees in their home.

46 Alma Abdul Hadi Jadallah (2015) Conflict Analysis of the Republic of Yemen for United National Country Team, June 2015

47 Oxfam (2014) Informal Actors, Community, and the State, December 2014

48 IASC (2015) Humanitarian Crisis in Yemen: Gender Alert July 2015.

49 UNFPA (2009) Country Assessment on Violence against Women UNFPA.

50 OCHA (2015b) Draft Humanitarian Needs Overview for 2016, OCHA: 2015.

51 IASC (2015) Humanitarian Crisis in Yemen: Gender Alert July 2015.

52 Rasha Jarhum, (2016) Status of Women during Conflict in Yemen: Reflections on WPS, UNSC 1325 and CEDAW Aspen Institute 2016 available at https://jarhum.files.wordpress.com/2016/03/yemen-wspand-cedaw-30-to-be.pdf

53 Alma Abdul Hadi Jadallah (2015) Conflict Analysis of the Republic of Yemen for United National Country Team, June 2015

54 OCHA (2015b) Draft Humanitarian Needs Overview for 2016, OCHA: 2015.

55 CARE (2015a) Rapid Gender Analysis of Yemen, June 2015.

56 UNHCR (2015) Yemen Situation Regional Refugee and Migration Response Plan

57 CARE (2015a) Rapid Gender Analysis of Yemen, June 2015.

58 Ministry of Public Health and Population and Central Statistical Organization (2015) National Health and Demographic Survey 2013, Sana'a, Yemen, July 2015

59 ICAN (2016) We will survive: Women's Rights and Civil Activism in Yemen's Endless War Brief 14, Winter 2016

60 Alma Abdul Hadi Jadallah (2015) Conflict Analysis of the Republic of Yemen for United National Country Team, June 2015

61 USAID (2014) Yemen Gender Assessment, January 2014, accessed Jan 2016 http://pdf.usaid.gov/pdfdocs/pa00jnrk.pdf

62 Alma Abdul Hadi Jadallah (2015) Conflict Analysis of the Republic of Yemen for United National Country Team, June 2015

63 IPTI (2016) Inclusive Peace \& Transition Initiative, Making Women Count - Not Just Counting Women, Graduate Institute Geneva, 29 Mar 2016

64 Wameedh Shakit (2013) Women's political participation in Yemen, Dreaming of a state, Yemen Country Report, LSE: London, Oct 2013. 
65 Ministry of Public Health and Population and Central Statistical Organization (2015) National Health and Demographic Survey 2013, Sana'a, Yemen, July 2015

66 Ministry of Public Health and Population and Central Statistical Organization (2015) National Health and Demographic Survey 2013, Sana'a, Yemen, July 2015

67 Ministry of Public Health and Population and Central Statistical Organization (2015) National Health and Demographic Survey 2013, Sana'a, Yemen, July 2015

68 ICAN (2016) We will survive: Women's Rights and Civil Activism in Yemen's Endless War Brief 14, Winter 2016

69 Rasha Jarhum,(2016) Status of Women during Conflict in Yemen: Reflections on WPS, UNSC 1325 and CEDAW Aspen Institute 2016 available at https://jarhum.files.wordpress.com/2016/03/yemen-wspand-cedaw-30-to-be.pdf

70 IASC (2015) Humanitarian Crisis in Yemen: Gender Alert July 2015.

71 Oxfam (2014) Informal Actors, Community, and the State December 2014

72Steven Zyck (2013) Conflict Assessment of the Republic of Yemen United Nations, 2013

73 OCHA (2016) Yemen Humanitarian Response Plan 2016

74 OCHA (2015b) Draft Humanitarian Needs Overview for 2016, OCHA: 2015.

75 OCHA (2016) Yemen Humanitarian Response Plan 2016

76 IASC (2015) Humanitarian Crisis in Yemen: Gender Alert July 2015.

77 OCHA (2015b) Draft Humanitarian Needs Overview for 2016, OCHA: 2015.

78 IASC GenCaP (2014) IDP registration - Gender, age and diversity considerations: Report of three discussion sessions.

79 Teresa Logue (2014) Yemen: Health Inequality Between the Genders. Yale Global Health Review, May 2014.

80 IASC (2015) Humanitarian Crisis in Yemen: Gender Alert July 2015.

81 Alma Abdul Hadi Jadallah (2015) Conflict Analysis of the Republic of Yemen for United National Country Team, June 2015

82 IASC (2015) Humanitarian Crisis in Yemen: Gender Alert July 2015.

83 OCHA (2015b) Draft Humanitarian Needs Overview for 2016, OCHA: 2015.

84 Rasha Jarhum,(2016) Status of Women during Conflict in Yemen: Reflections on WPS, UNSC 1325 and CEDAW Aspen Institute 2016 available at https://jarhum.files.wordpress.com/2016/03/yemen-wspand-cedaw-30-to-be.pdf

85 Alma Abdul Hadi Jadallah (2015) Conflict Analysis of the Republic of Yemen for United National Country Team, June 2015

86 This was reported in focus group discussion conducted in Hajjah.

87 UNDP (2016) Yemen: Yemen Resilience Monitor: Communities coping with Conflict, April 2016

88 UNDP (2016) Yemen: Yemen Resilience Monitor: Communities coping with Conflict, April 2016

89 OCHA (2015b) Draft Humanitarian Needs Overview for 2016, OCHA: 2015.

90 OCHA (2015b) Draft Humanitarian Needs Overview for 2016, OCHA: 2015.

91 OCHA (2015b) Draft Humanitarian Needs Overview for 2016, OCHA: 2015.

92 Ministry of Public Health and Population and Central Statistical Organization (2015) National Health and Demographic Survey 2013, Sana'a, Yemen, July 2015

93 Ministry of Public Health and Population and Central Statistical Organization (2015) National Health and Demographic Survey 2013, Sana'a, Yemen, July 2015

94 Alma Abdul Hadi Jadallah (2015) Conflict Analysis of the Republic of Yemen for United National Country Team, June 2015

95 OCHA (2015b) Draft Humanitarian Needs Overview for 2016, OCHA: 2015.

96 OCHA (2015b) Draft Humanitarian Needs Overview for 2016, OCHA: 2015. 
97 CARE (2015a) Rapid Gender Analysis of Yemen, June 2015.

98 Alma Abdul Hadi Jadallah (2015) Conflict Analysis of the Republic of Yemen for United National Country Team, June 2015, confirmed by focus group discussions conducted as part of this assessment.

99 Alma Abdul Hadi Jadallah (2015) Conflict Analysis of the Republic of Yemen for United National Country Team, June 2015

100 CARE (2015a) Rapid Gender Analysis of Yemen, June 2015.

101 Alma Abdul Hadi Jadallah (2015) Conflict Analysis of the Republic of Yemen for United National Country Team, June 2015

102 OCHA (2015b) Draft Humanitarian Needs Overview for 2016, OCHA: 2015.

103 Alma Abdul Hadi Jadallah (2015) Conflict Analysis of the Republic of Yemen for United National Country Team, June 2015

104 Human Rights Watch (2016) Country Summary Yemen, January 2016. 


\section{ACKNOWLEDGEMENTS}

This report was written by Wolfgang Gressmann who was the project lead consultant and data analyst in the research. The field assessment in Yemen was coordinated by Thabet Bagash and his team of talented and dedicated staff: Abdo Yasin Salih Hulaibi, Abdulfatah Salih Ahmed AlQubati, Rasha Radman Al-Qadasi, Mohammed Abdulsalam Sadeq (Technical and Support Team); Ibraheem Ahmed Alaswadi, Sameer Mohammed Al-galal, Anwar Ahmed Alswaidi, Nada Humaid Nasser, Huda Ahmed Al-hakami, Fathia Ali Sallam (Taiz and Hajja Team, data collection); Al-Khader Ahmed Mohammed Alhadad, Raja'a Nasser Ahmed, Wala'a Ahmed Alhajj, Donia Abduljabar Mohammed, Fadhle Mohsen Nasher, Mohsen Abdallah Awad (Aden and Abyan Team, data collection).

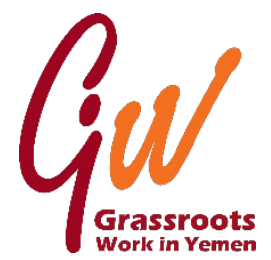

Project team Oxfam: Sajjad Mohammad Sajid, Zorica Skakun, Abigael Baldoumas, Rehab AlThamari, Tefera Mekonnen. Oxfam acknowledges the assistance of Ghaidaa Alabsi, Arvind Kumar, Fausto Aarya De Santis, Moath Jamal, Fatima Taher, Reena Haitham and Soman Moodley.

Project team CARE International: Wael Ibrahim, Lina Y. Al-Saffi, Fasil Demeke, Isadora Quay.

GenCap: Deborah Clifton and Rachel Agelou.

Thanks to GenCap Deborah Clifton for her support.

The Gender Standby Capacity Project (GenCap) is an IASC initiative created in 2007 in collaboration with the Norwegian Refugee Council (NRC), and seeks to facilitate and strengthen capacity and leadership of humanitarians to undertake and promote gender equality programming to ensure the distinct needs of women, girls, boys and men of all ages are taken into account in humanitarian action at global, regional and country levels.

Gender Capacity Advisers are deployed to support the Humanitarian Coordinator, Humanitarian Country Teams, UN agencies, cluster leads, NGOs and governments.

GenCap Advisers can be deployed in the initial stages of sudden-onset emergencies as well as in protracted or recurring humanitarian situations.

For further information concerning the GenCap project please go to https://www.humanitarianresponse.info/fr/coordination/gencap/gencap-what-we-do

In addition, special thanks are extended to Stephanie Laryea Humanitarian Affairs Officer (Assessment/Monitoring), United Nations Office for the Coordination of Humanitarian Affairs $(\mathrm{OCHA})$ Yemen, and the various national and international organizations and authorities and government agencies in Yemen who supported this assessment and its validation process. 


\section{Research reports}

This research report was written to share research results, to contribute to public debate and to invite feedback on development and humanitarian policy and practice. It does not necessarily reflect the policy positions of the publishing organizations. The views expressed are those of the author and not necessarily those of the publishers.

For more information, or to comment on this report, email Dr Abigael Baldoumas at ABaldoumas@oxfam.org.uk

() Oxfam International October 2016

This publication is copyright but the text may be used free of charge for the purposes of advocacy, campaigning, education, and research, provided that the source is acknowledged in full. The copyright holder requests that all such use be registered with them for impact assessment purposes. For copying in any other circumstances, or for re-use in other publications, or for translation or adaptation, permission must be secured and a fee may be charged. Email policyandpractice@oxfam.org.uk.

The information in this publication is correct at the time of going to press.

Published by Oxfam GB for Oxfam International under ISBN 978-0-85598-812-8 in October 2016.

Oxfam GB, Oxfam House, John Smith Drive, Cowley, Oxford, OX4 2JY, UK.

\section{OXFAM}

Oxfam is an international confederation of 20 organizations networked together in more than 90 countries, as part of a global movement for change, to build a future free from the injustice of poverty. Please write to any of the agencies for further information, or visit www.oxfam.org. 